\title{
Hydrolytic Dehydrogenation of Ammonia Borane Attained by Ru-Based Catalysts: An Auspicious Option to Produce Hydrogen from a Solid Hydrogen Carrier Molecule
}

\author{
Miriam Navlani-García ${ }^{1, *(\mathbb{D})}$, David Salinas-Torres ${ }^{2}$ and Diego Cazorla-Amorós ${ }^{1}$ (D) \\ 1 Department of Inorganic Chemistry and Materials Institute, University of Alicante, 03080 Alicante, Spain; \\ cazorla@ua.es \\ 2 Department of Physical Chemistry and Materials Institute, University of Alicante, 03080 Alicante, Spain; \\ david.salinas@ua.es \\ * Correspondence: miriam.navlani@ua.es; Tel.: +34-965-903-400 (ext. 9150)
}

Citation: Navlani-García, M.; Salinas-Torres, D.; Cazorla-Amorós, D. Hydrolytic Dehydrogenation of Ammonia Borane Attained by Ru-Based Catalysts: An Auspicious Option to Produce Hydrogen from a Solid Hydrogen Carrier Molecule. Energies 2021, 14, 2199. https://doi.org/10.3390/ en14082199

Academic Editor: Dmitri A. Bulushev

Received: 21 March 2021 Accepted: 13 April 2021 Published: 15 April 2021

Publisher's Note: MDPI stays neutral with regard to jurisdictional claims in published maps and institutional affiliations.

Copyright: (c) 2021 by the authors. Licensee MDPI, Basel, Switzerland. This article is an open access article distributed under the terms and conditions of the Creative Commons Attribution (CC BY) license (https:/ / creativecommons.org/licenses/by/ $4.0 /)$.

\begin{abstract}
Chemical hydrogen storage stands as a promising option to conventional storage methods. There are numerous hydrogen carrier molecules that afford satisfactory hydrogen capacity. Among them, ammonia borane has attracted great interest due to its high hydrogen capacity. Great efforts have been devoted to design and develop suitable catalysts to boost the production of hydrogen from ammonia borane, which is preferably attained by Ru catalysts. The present review summarizes some of the recent Ru-based heterogeneous catalysts applied in the hydrolytic dehydrogenation of ammonia borane, paying particular attention to those supported on carbon materials and oxides.
\end{abstract}

Keywords: ammonia borane; hydrogen production; hydrogen carrier; hydrogen storage; Ru nanoparticles

\section{Introduction}

Energy demand has constantly increased in the last decades, which is closely linked to the expanding population and increasing prosperity. Currently, about $80 \%$ of the world's energy supply comes from fossil fuels (i.e., coal, oil, and natural gas). However, their utilization is inevitably associated with the emission of hazardous gases, which drives the current global warming crisis. Currently, nearly $100 \%$ of the total $\mathrm{CO}_{2}$ emissions originate from the combustion and processing of fossil fuels [1], and its concentration in the atmosphere, which has experienced a great increase since the start of the Industrial Revolution, is nowadays higher than 400 ppm [2].

Hence, the tremendous concerns about the environmental issues related to the use of fossil fuels, together with their finite nature, is fostering the search toward the deployment of renewable energy sources. Such an ambitious goal has been the central focus of many investigations. In this sense, the use of hydrogen has tremendous hope for the use of renewable energies in different industrial applications and the transport sector. This is reflected in the constantly increasing number of publications in which its supremacy as an outstanding energy vector is highlighted [3-7].

The use of hydrogen, produced from renewable energy sources, has significant benefits. Its use has zero emission of greenhouse gases and it produces only water as a by-product. Additionally, it has a high energy storage capacity on a gravimetric basis (120 MJ $/ \mathrm{kg})$, which is much greater than those of gasoline $(44.4 \mathrm{MJ} / \mathrm{kg})$, diesel $(45.4 \mathrm{MJ} / \mathrm{kg})$, biodiesel oil (42.2 MJ/kg), and natural gas (53.6 MJ/kg) [8]. However, against all the benefits of hydrogen, its low volumetric energy density (i.e., $0.01 \mathrm{MJ} / \mathrm{L}$ at standard temperature and pressure conditions (STP)), which is much lower than those of common fuels (gasoline (34.2 MJ/L), diesel (34.6 MJ/L), biodiesel oil (33 MJ/L), and natural gas (0.0364 MJ/L)) limits its utilization as a fuel at ambient conditions. There are different options to increase 
the hydrogen energy density so that it can meet the target set by the U.S. Department of Energy (DOE), which fixes the ultimate onboard hydrogen storage for light-duty fuel cell vehicles at $0.065 \mathrm{~kg} \mathrm{H}_{2} / \mathrm{kg}$ system and $0.050 \mathrm{~kg} / \mathrm{L}$, in gravimetric and volumetric basis, respectively [9]. The most used options encompass physical methods such as hydrogen liquefaction, compression, and adsorption in porous materials $[10,11]$. However, the harsh conditions (such as very high pressure or extremely low temperature), and the high cost associated with the infrastructure needed for the safe handling and storage of hydrogen are important drawbacks of such physical storage methods.

In contrast, chemical storage methods stand up as a promising option, which is particularly important for onboard automotive applications, in which the technologies used in the physical methods do not fully meet the DOE targets for safe and inexpensive hydrogen storage [12,13].

Chemical hydrogen storage refers to those processes in which molecular hydrogen is released through a chemical reaction that starts when the hydrogen-containing molecule (i.e., hydrogen carrier) is subjected to thermal or catalytic decomposition [14].

There are various hydrogen carrier molecules in both the liquid and solid phase. Notable examples of those molecules, together with their hydrogen content (in wt. \%) are included in Table 1.

Table 1. Examples of hydrogen storage molecules.

\begin{tabular}{cccc}
\hline $\begin{array}{c}\text { Hydrogen Storage } \\
\text { Material }\end{array}$ & State & $\begin{array}{c}\text { Hydrogen Content } \\
\text { in wt. } \%\end{array}$ & Reference \\
\hline $\mathrm{NH}_{3} \mathrm{BH}_{3}$ & Solid & 19.5 & {$[15,16]$} \\
$\mathrm{LiBH}_{4}$ & Solid & 18.4 & {$[17,18]$} \\
$\mathrm{NaBH}_{4}$ & Solid & 10.8 & {$[19,20]$} \\
$\mathrm{MgH}_{2}$ & Solid & 7.6 & {$[21,22]$} \\
$\mathrm{NH}_{3}$ & Liquid & 17.6 & {$[23,24]$} \\
$\mathrm{CH}_{3} \mathrm{OH}$ & Liquid & 12.6 & {$[25,26]$} \\
$\mathrm{H}_{2} \mathrm{NH}_{2}$ & Liquid & 12.5 & {$[27,28]$} \\
$\mathrm{H}_{2} \mathrm{O}$ & Liquid & 11.1 & {$[29,30]$} \\
$\mathrm{HCOOH}$ & Liquid & 4.4 & {$[31-33]$} \\
\hline
\end{tabular}

Seeking and exploring new hydrogen storage options are in continuous progress and significant advances related to reversible hydrogen storage have been recently achieved [34-37]. In this review, we cover some of the most relevant recent strategies on hydrogen production from $\mathrm{NH}_{3} \mathrm{BH}_{3}$ (ammonia borane, $\mathrm{AB}$ ), which is the simplest nitrogen boron hydrogen compound [38-40], and one of the most fruitfully investigated solid-state hydrogen-rich molecules.

$\mathrm{AB}$ is a white crystalline solid at room temperature, which was first prepared by Shore and Parry in 1955 [41], and it has received tremendous attention due to several advantages compared to other hydrogen carrier molecules such as its high hydrogen content (19.6 wt. \%; each equivalent yielding up to 3 equivalents of hydrogen), low molecular weight $\left(30.87 \mathrm{~g} \mathrm{~mol}^{-1}\right)$, its stability in solid-state, and high solubility in water. Furthermore, it is nonexplosive and non-flammable under standard conditions. $\mathrm{AB}$ has a high melting point of $112{ }^{\circ} \mathrm{C}$ and a density of $0.74 \mathrm{~g} \mathrm{~cm}^{-3}$ [38].

$\mathrm{AB}$ has an equal number of protic $\mathrm{H}^{\delta+}(\mathrm{N}-\mathrm{H})$ and hydridic $\mathrm{H}^{\delta-}(\mathrm{B}-\mathrm{H})$ hydrogens in intra- and intermolecular interactions. It has heteropolar $(\mathrm{N}-\mathrm{H} \cdots \mathrm{H}-\mathrm{B})$ and homopolar (B-H $\cdots \mathrm{H}-\mathrm{B})$ dihydrogen interactions, which are the origin of the intra- and intermolecular dehydrogenation of $\mathrm{AB}$ [42]. It also has a strong $\mathrm{B}-\mathrm{N}$ bond, so that the release of hydrogen is more favored than the dissociation into $\mathrm{NH}_{3}$ and $\mathrm{BH}_{3}$ under most conditions [43]. $\mathrm{AB}$ can be synthesized in three different ways (i.e., Lewis acid-Lewis base exchange, saltmetathesis followed by hydrogen release, and isomerization of the diammonate of diborane $\left.\left(\left[\mathrm{H}_{2} \mathrm{~B}\left(\mathrm{NH}_{3}\right)_{2}\right]^{+}\left[\mathrm{BH}_{4}\right]^{-}\right)\right)[38]$.

The dehydrogenation of $\mathrm{AB}$ can be performed by either thermolysis, a process which needs much thermal energy (it requires temperatures as high as $200^{\circ} \mathrm{C}$ ), or solvolysis 
in protic solvents (i.e., hydrolysis in water (Equation (1)) and methanolysis in methanol (Equation (2)) and dehydrocoupling in nonprotic solvents (Equations (3) and (4)) [44].

$$
\begin{gathered}
\mathrm{NH}_{3} \mathrm{BH}_{3}(\mathrm{aq})+2 \mathrm{H}_{2} \mathrm{O}(\mathrm{l}) \rightarrow \mathrm{NH}_{4} \cdot \mathrm{BO}_{2}(\mathrm{aq})+3 \mathrm{H}_{2}(\mathrm{~g}) \\
\mathrm{NH}_{3} \mathrm{BH}_{3}(\mathrm{sol})+4 \mathrm{CH}_{3} \mathrm{OH}(\mathrm{l}) \rightarrow \mathrm{NH}_{4} \cdot \mathrm{B}\left(\mathrm{OCH}_{3}\right)_{4}(\mathrm{sol})+3 \mathrm{H}_{2}(\mathrm{~g}) \\
n \mathrm{NH}_{3} \mathrm{BH}_{3}(\mathrm{sol}) \rightarrow\left(\mathrm{NH}_{2} \mathrm{BH}_{2}\right)_{n}(\mathrm{~s} \text { or sol })+n \mathrm{H}_{2}(\mathrm{~g}) \\
n \mathrm{NH}_{3} \mathrm{BH}_{3}(\mathrm{sol}) \rightarrow(\mathrm{NHBH})_{n}(\mathrm{~s} \text { or sol })+n \mathrm{H}_{2}(\mathrm{~g})
\end{gathered}
$$

$\mathrm{AB}$ solvolysis can afford 3 equivalents of molecular hydrogen at moderate temperatures upon utilization of a proper catalyst, so this is the preferred option. The dehydrogenation of amine-borane adducts catalyzed by transition-metals dates back to the late 1980s [45], but its application in the production of hydrogen is still drawing great interest in the research community, as can be seen in the increasing number of publications reported per year (see Figure 1).

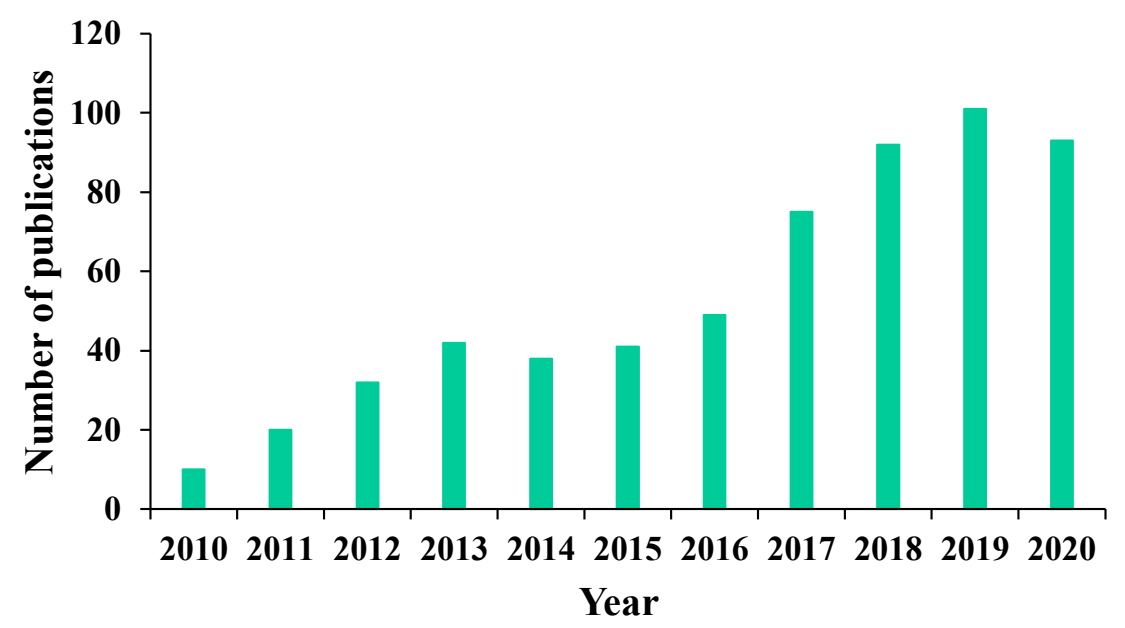

Figure 1. Number of publications in the last 10 years found on the ISI Web of Science for the entry "hydrogen production and ammonia borane".

Both homogeneous and heterogeneous catalytic systems have been explored, but the advantages of heterogeneous catalysts make these systems preferred from a practical point of view. There is vast literature reported on the hydrolytic dehydrogenation of $A B$, highlighting those contributions made by Yamashita et al. [46-54], Özkar et al. [55-58], and Xu et al. [44,59-62].

Among the heterogeneous catalysts, systems based on ruthenium nanoparticles (NPs) have shown outstanding performances. Ru-based catalysts usually achieve complete $A B$ dehydrogenation, producing $\sim 3$ equivalents of hydrogen in short reaction times, and with thermo-controllable reaction rates. The hydrolysis rate is also frequently related to the amount of catalyst and $\mathrm{AB}$, but the hydrolysis rate is frequently found as zero-order relation or quasi-zero-order relation with the concentration of $\mathrm{AB}$ [63].

It is worth mentioning that despite the intense efforts devoted to unveiling the mechanism of the hydrolytic dehydrogenation of ammonia borane, there are still some aspects that remain unclear (e.g., rate-determining steps, the order of bond cleavages, etc.) [64]. For instance, $\mathrm{Xu}$ et al. postulated that the interaction between $\mathrm{AB}$ molecules and the surface of the metal active phase gives rise to the formation of activated complex species, which are attacked by a molecule of $\mathrm{H}_{2} \mathrm{O}$, leading to the concerted dissociation of the $\mathrm{B}-\mathrm{N}$ bond and the hydrolysis of the $\mathrm{BH}_{3}$ intermediate to form $\mathrm{BO}_{2}$, releasing $\mathrm{H}_{2}$ [65]. Fu et al. proposed a mechanism that proceeds via an almost self-powered process that involves the formation of $\mathrm{BH}_{3} \mathrm{OH}^{-}$and $\mathrm{NH}_{4}{ }^{+}$, followed by the attack of adjacent $\mathrm{H}_{2} \mathrm{O}$ to generate $\mathrm{H}_{2}$ [66]. Na et al. suggested that the mechanism is very similar to that of the hydrolytic dehydrogenation 
of sodium borohydride, and proceeds via dissociative adsorption of ammonia borane on $\mathrm{Ru}$ surface [67]. More recently, Liu et al. claimed that the hydrogen production from $\mathrm{AB}$ attained by noble metal catalysts occurs via the following steps: (1) $\mathrm{AB}$ molecules interact with the surface of the catalyst to form a complex; (2) A molecule of $\mathrm{H}_{2} \mathrm{O}$ attacks to AB-catalyst complex; and (3) $\mathrm{AB}$ and $\mathrm{H}_{2} \mathrm{O}$ each lose a hydrogen atom to form $\mathrm{H}_{2}$. Such a mechanism is illustrated in Figure 2 [63].

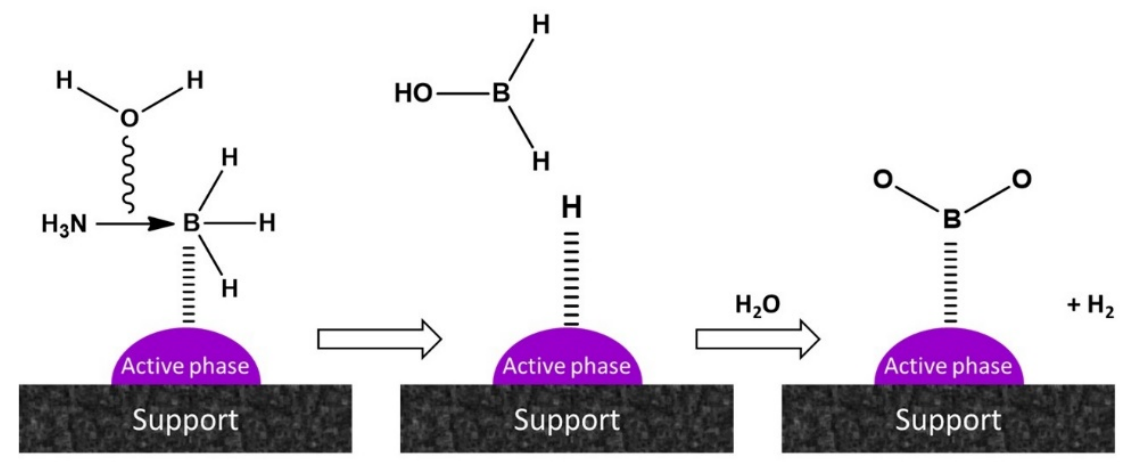

Figure 2. Mechanism proposed for hydrogen production from the hydrolysis of ammonia borane (AB). Adapted from [63].

It is evident that the catalyst's nature plays a crucial role in controlling the whole reaction. Most of the studies reported on Ru-based catalysts for the hydrolytic dehydrogenation of $\mathrm{AB}$ are focused on elucidating the role of the features of the metal active phase (i.e., size, morphology, incorporation of a second and third metal in the nanoparticles, etc.), while less attention has been paid to the properties of the support. We divided this manuscript into several sections, which contain a review of representative catalytic systems based on monometallic Ru NPs and supports of a diverse nature, which have been used for the hydrolytic dehydrogenation of AB. As a summary, Table 2 includes representative examples of Ru-based catalysts supported on carbon materials, oxides, metal organic frameworks (MOF), and some other less explored supports, together with the turnover frequency values achieved (TOF; in $\mathrm{mol}_{\mathrm{H} 2} \cdot \mathrm{mol}_{\mathrm{Ru}}{ }^{-1} \cdot \mathrm{min}^{-1}$ ) and the calculated activation energy $\left(\mathrm{Ea}\right.$; in $\left.\mathrm{kJ} \mathrm{mol}^{-1}\right)$.

Table 2. Catalytic activity of heterogeneous Ru-based catalysts used for the hydrolytic dehydrogenation of ammonia borane $(\mathrm{AB})$.

\begin{tabular}{|c|c|c|c|}
\hline Catalyst & $\mathrm{TOF}\left(\mathrm{mol}_{\mathrm{H} 2} \cdot \mathrm{mol}_{\mathrm{Ru}}{ }^{-1} \cdot \mathrm{min}^{-1}\right)$ & $\mathrm{Ea}\left(\mathrm{kJ} \mathrm{mol}{ }^{-1}\right)$ & Reference \\
\hline Ru/Graphene & 100 & 11.7 & [68] \\
\hline $\mathrm{Ru} / \mathrm{NC}-\mathrm{Fe}$ & 102.9 & 47.42 & [69] \\
\hline $\mathrm{Ru} /$ nanodiamond & 229 & 50.7 & [70] \\
\hline CF-BT-Ru & 322 & 32.41 & [71] \\
\hline Ru(0)@MWCNT & 329 & 33 & [72] \\
\hline $\mathrm{Ru} / \mathrm{BC}-\mathrm{hs}$ & 354 & 45.72 & [73] \\
\hline $\mathrm{Ru} / \mathrm{PPC}$ & 413 & 35.2 & [74] \\
\hline $\mathrm{Ru} / \mathrm{C}$ & 429.5 & 34.81 & [75] \\
\hline $\mathrm{Ru} / \mathrm{HPCM}$ & 440 & 43.0 & [76] \\
\hline $\mathrm{Ru} / g-\mathrm{C}_{3} \mathrm{~N}_{4}$ & 459.3 & 37.4 & [77] \\
\hline Ru/Graphene & 600 & 12. 7 & [78] \\
\hline $\mathrm{Ru} / \mathrm{C}(800)$ & 670 & 14.3 & [79] \\
\hline $\mathrm{Ru} / \mathrm{BC}-1$ & 718 & 22.8 & [80] \\
\hline $\mathrm{Ru} / \mathrm{NPC}$ & 813 & 24.95 & [81] \\
\hline $\mathrm{Ru}(0) / \mathrm{SiO}_{2}-\mathrm{CoFe}_{2} \mathrm{O}_{4}$ & 172 & 45.6 & [82] \\
\hline $\mathrm{Ru} @ \mathrm{SiO}_{2}$ & 200 & 38.2 & [83] \\
\hline $\mathrm{Ru}(1) @ S 1 B-C 10$ & 202.4 & 24.13 & [84] \\
\hline
\end{tabular}


Table 2. Cont.

\begin{tabular}{|c|c|c|c|}
\hline Catalyst & TOF $\left(\mathrm{mol}_{\mathrm{H} 2} \cdot \mathrm{mol}_{\mathrm{Ru}}{ }^{-1} \cdot \mathrm{min}^{-1}\right)$ & $\mathrm{Ea}\left(\mathrm{kJ} \mathrm{mol}{ }^{-1}\right)$ & Reference \\
\hline Ru@SBA-15 & 316 & 34.8 & [85] \\
\hline $\mathrm{Fe}_{3} \mathrm{O}_{4} @ \mathrm{SiO}_{2}-\mathrm{NH}_{2}-\mathrm{Ru}$ & 617 & 15.05 & [86] \\
\hline $\mathrm{Ru} @ \mathrm{Al}_{2} \mathrm{O}_{3}$ & 83.3 & - & [87] \\
\hline $\mathrm{Ru} / \gamma-\mathrm{Al}_{2} \mathrm{O}_{3}$ & 256 & - & [88] \\
\hline $\mathrm{Ru} / \mathrm{Al}_{2} \mathrm{O}_{3}-\mathrm{NFs}$ & 327 & 36.1 & [89] \\
\hline $\mathrm{Ru}(0) / \mathrm{TiO}_{2}$ & 241 & 70 & [90] \\
\hline $\mathrm{Ru}^{0} / \mathrm{HfO}_{2}$ & 170 & 65 & [91] \\
\hline $\mathrm{Ru} / \mathrm{MIL}-96$ & 231 & 47.7 & [92] \\
\hline Ru@MIL-53(Cr) & 260.8 & 28.9 & [93] \\
\hline Ru@MIL-53(Al) & 266.9 & 33.7 & [93] \\
\hline $\mathrm{Ru} / \mathrm{MIL}-53(\mathrm{Al})-\mathrm{NH}_{2}$ & 287 & 30.5 & [94] \\
\hline $\mathrm{Ru} / \mathrm{PAF}-72$ & 294 & - & [95] \\
\hline $\mathrm{Ru} / \mathrm{Mg}_{2} \mathrm{Al}-\mathrm{LDH}-\mathrm{h}$ & 85.7 & 50.3 & [96] \\
\hline $\mathrm{Ru} / \mathrm{Mg}_{1} \mathrm{Al}_{1}$-LDHs & 137.1 & 30.8 & [97] \\
\hline CF-BT-Ru & 322 & 32.41 & [71] \\
\hline
\end{tabular}

\section{Hydrolytic Dehydrogenation of Ammonia Borane (AB) over Carbon Material-Supported Catalysts}

Several catalytic supports have been explored for the synthesis of highly efficient catalysts for the hydrolytic dehydrogenation of $\mathrm{AB}$. Carbon materials are one of the most intensively studied and the resulting catalysts have given very interesting results.

Akbayrak and Özkar explored the performance of catalysts supported on multiwalled carbon nanotubes $(\mathrm{Ru}(0) @ M W C N T)$ by evaluating the activity of in-situ formed Ru nanoparticles (NPs) [72]. The resulting NPs had an average particle size range of 1.4-3.0 nm and were well-dispersed on the support. The effect of the Ru content was evaluated by checking the activity (in $\mathrm{mL}$ of $\mathrm{H}_{2} / \mathrm{min}$ ) of catalysts with metal contents of $0.73,1.47,1.91$, 2.26 , and $2.83 \mathrm{wt}$. \%. Among those investigated, the sample with $1.91 \mathrm{wt}$. \% displayed the best activity, with a TOF $=329 \mathrm{~min}^{-1}\left(\mathrm{~mol}_{\mathrm{H} 2} \cdot \mathrm{mol}_{\mathrm{Ru}}{ }^{-1} \cdot \mathrm{min}^{-1}\right)$. That catalyst was evaluated during four consecutive reaction cycles and it preserved $41 \%$ of its initial activity. Doe et al. also checked the performance of MWCNT-supported Ru catalysts with $\mathrm{Ru}\left(\mathrm{NH}_{3}\right)_{6} \mathrm{Cl}_{3}$ as the metal precursor and using electrostatic adsorption (EA) and incipient wetness impregnation (IWI) methods [98]. Additionally, catalysts based on activated carbon and $\mathrm{SiO}_{2}$ were prepared as reference materials. The Ru NPs were located on the external surface after both EA and IWI, and a smaller average size was achieved for the EA ( 2 and $3 \mathrm{~nm}$ for $\mathrm{Ru} / \mathrm{MWCNT}-\mathrm{EA}$ and Ru/MWCNT-IWI, respectively). Checking the performance of three sets of catalysts supported on MWCNTs, activated carbon, and $\mathrm{SiO}_{2}$ with various average NPs size, it was observed that in all cases the catalysts with larger NPs attained higher reaction rates (expressed as turnover rates in $\mathrm{mol}_{\mathrm{H} 2} \cdot \mathrm{mol}_{\text {surface } \mathrm{Ru}}{ }^{-1} \cdot \mathrm{s}^{-1}$ ), and higher TOF values were achieved for the Ru/MWCNT catalysts. Among those evaluated in that study, $\mathrm{Ru} / \mathrm{MWCNTs-EA}$ produced the highest initial TOF value and the lowest activation energy, which was attributed to the hydrogen spillover taking place on metal NPs supported on CNTs.

Cheng et al. reported a simple method for the preparation of a $\mathrm{Ru} /$ graphene catalyst synthesized from graphene oxide and $\mathrm{RuCl}_{3}$ using a one-step co-reducing approach with methylamine borane (MeAB) [68]. The resulting catalyst was compared to those synthesized by using different reducing agents, namely $\mathrm{AB}$ and $\mathrm{NaBH}_{4}$. It was observed that the sample prepared with MeAB provided better results than those using $\mathrm{AB}$ or $\mathrm{NaBH}_{4}$, which was attributed to a better control over nucleation and growth processes. It was determined that the average NPs size was 1.2, 1.7, and $2.0 \mathrm{~nm}$ for the catalysts reduced with $\mathrm{MeAB}, \mathrm{AB}$, and $\mathrm{NaBH}_{4}$, respectively, suggesting that the size of the NPs increased as the reducing agent became stronger. The catalyst reduced with MeAB had a TOF of $100 \mathrm{~mol}_{\mathrm{H} 2} \cdot \mathrm{mol}_{\mathrm{Ru}}{ }^{-1} \cdot \mathrm{min}^{-1}$, and activation energy of $11.7 \mathrm{~kJ} \mathrm{~mol}^{-1}$, and it retained $72 \%$ of its initial activity after four reaction cycles. The same research group followed a very similar 
one-step co-reducing approach using ascorbic acid to synthesize $\mathrm{Ru}$ /graphene catalysts, which resulted in much higher TOF values of $600 \mathrm{~mol}_{\mathrm{H} 2} \cdot \mathrm{mol}_{\mathrm{Ru}}{ }^{-1} \cdot \mathrm{min}^{-1}$ and activation energy of $12.7 \mathrm{~kJ} \mathrm{~mol}^{-1}$ [78], which pointed out the importance of the reducing agent in controlling the final catalytic performance. The high TOF value achieved by $\mathrm{Ru} /$ graphene was attributed to the narrow size distribution of the Ru NPs and the utilization of graphene as a suitable support.

In the study of Ma and co-workers, [75] ligand-free Ru NPs supported on carbon black were prepared in-situ from the reduction of the metal precursor (i.e., $\mathrm{RuCl}_{3}$ ) by $\mathrm{AB}$ concomitantly with its hydrolysis. The resulting catalyst had an average nanoparticle size of $1.7 \mathrm{~nm}$ and showed a TOF of $429.5 \mathrm{~mol}_{\mathrm{H} 2} \cdot \mathrm{mol}_{\mathrm{Ru}}{ }^{-1} \cdot \mathrm{min}^{-1}$. In that case, the reusability of the catalyst was checked during five consecutive reaction runs, after which it preserved $43.1 \%$ of its initial activity. The results of the characterization of the spent catalyst indicated that there were neither metal leaching nor aggregation of the NPs, so that the activity loss was attributed to an increasing concentration of the reaction products (i.e., metaborate and $\mathrm{Cl}^{-}$ions) and their adsorption on the surface of the NPs. Furthermore, it was postulated that the increase in the viscosity in the solution after several reaction cycles could impede the diffusion of the reactant molecules and their collision with the Ru active sites.

Sun et al. studied the performance of poly(N-vinyl-2-pyrrolidone) (PVP)-stabilized Ru NPs loaded onto bamboo leaf-derived porous carbon ( $\mathrm{Ru} / \mathrm{BC}$ ) [80]. In that case, the NPs were synthesized by in-situ reduction with $\mathrm{AB}$ using $\mathrm{RuCl}_{3} \cdot \mathrm{nH}_{2} \mathrm{O}$ as a metal precursor and with various PVP content (i.e., 0, 1, 3, 5, or $10 \mathrm{mg}$ ), which was used to avoid the agglomeration of the NPs. The catalysts with the best activity among those investigated (i.e., Ru/BC stabilized with $1 \mathrm{mg}$ of PVP) displayed a TOF of $718 \mathrm{~mol}_{\mathrm{H} 2} \cdot \mathrm{mol}_{\mathrm{Ru}}{ }^{-1} \cdot \mathrm{min}^{-1}$, and retained nearly $56 \%$ of the initial catalytic activity after 10 consecutive reaction cycles. That stability was much better than that of the PVP-free catalyst, which indicated the important role of PVP in enhancing the recyclability of the catalysts by preventing the agglomeration of the NPs. The same research group also investigated the performance of nitrogen-doped (N-doped) porous carbon materials [81]. The support was prepared by hydrothermal treatment of hydrochloride semicarbazide and glucose, and it was subsequently loaded with the metal precursor. The resulting $\mathrm{Ru} / \mathrm{NPC}$ catalyst completed the dehydrogenation reaction in $90 \mathrm{~s}$ at room temperature, reaching a TOF of $813 \mathrm{~mol}_{\mathrm{H} 2} \cdot \mathrm{mol}_{\mathrm{Ru}}{ }^{-1} \cdot \mathrm{min}^{-1}$. The stability of the catalyst was checked by performing five consecutive runs, after which $67.3 \%$ of the initial activity was preserved, and the activity decay was attributed to the agglomeration of the NPs.

Yamashita et al. addressed the preparation of highly efficient $\mathrm{Ru}$ /carbon catalysts prepared by pyrolysis of a supported Ru complex (i.e., tri(2,2-bipyridyl) ruthenium (II) chloride hexahydrate) [79]. In that study, the Ru catalysts were prepared by impregnating a commercial activated carbon with the metal precursor and subsequent decomposition of the metal complex by carrying out a heat treatment at temperatures ranging from 600 to $1000{ }^{\circ} \mathrm{C}$ (catalysts denoted as Ru/C(600)-(1000)). Transmission Electron Microscopy (TEM) analysis confirmed the formation of Ru NPs even for the lowest temperatures used for the decomposition of the metal complex. The average NP size strongly depended on the decomposition temperature and ranged from 3.8 to $13.5 \mathrm{~nm}$ for the $\mathrm{Ru} / \mathrm{C}$ catalysts. Two additional reference samples were also synthesized: $\mathrm{Ru} / \mathrm{C}(\mathrm{imp})$ prepared by the same protocol using $\mathrm{Ru}(\mathrm{NO})\left(\mathrm{NO}_{3}\right)_{3}$ as the metal precursor, and the $\mathrm{Ru} / \mathrm{SiO}_{2}$ catalyst prepared from $\mathrm{Ru}(\mathrm{bpy})_{3}{ }^{2+}$ and commercial fumed silica, with NP size of 3.3 and $2.0 \mathrm{~nm}$, respectively. The results of the catalytic activity indicated that complete conversion of $\mathrm{AB}$ was attained with $\mathrm{Ru} / \mathrm{C}(800), \mathrm{Ru} / \mathrm{C}(900)$ and $\mathrm{Ru} / \mathrm{C}(1000)$, whereas it was not achieved with $\mathrm{Ru} / \mathrm{C}(600)$, $\mathrm{Ru} / \mathrm{C}(700), \mathrm{Ru} / \mathrm{C}(\mathrm{imp})$, and $\mathrm{Ru} / \mathrm{SiO}_{2}$. That observation led the authors to conclude that under the experimental conditions used, relatively large NPs were preferred for the reaction. Among those investigated, $\mathrm{Ru} / \mathrm{C}(800)$ showed the most promising activity with an average TOF number of $670 \mathrm{~mol}_{\mathrm{H} 2} \cdot \mathrm{mol}_{\mathrm{Ru}}{ }^{-1} \cdot \mathrm{min}^{-1}$. That catalyst achieved $100 \%$ of conversion even after four consecutive reaction runs, but the reaction rate was progressively sluggish. A summary of the results of the catalytic activity of the materials assessed in that work is 
plotted in Figure 3. It was also concluded that the electronic properties of Ru NPs played an important role in controlling the catalytic performance. It was claimed that $\mathrm{Ru} / \mathrm{C}(800)$ had an optimum proportion of oxidized Ru species, which are important in the reaction.

(a)

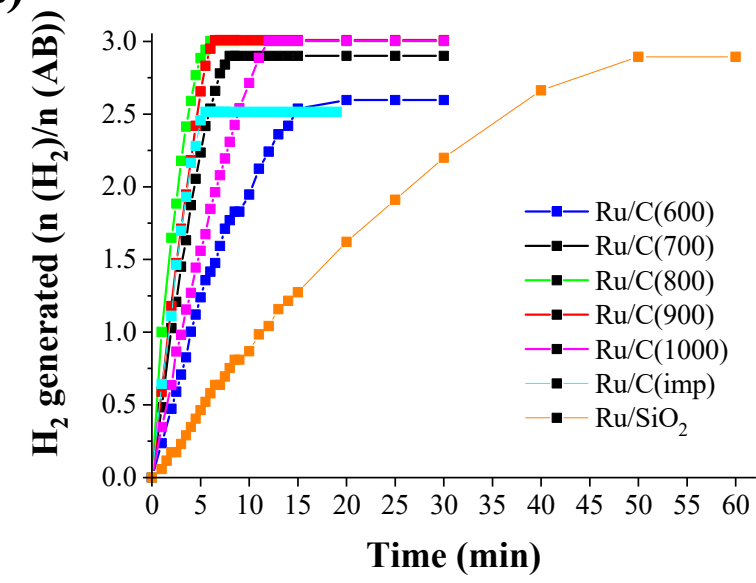

(b)

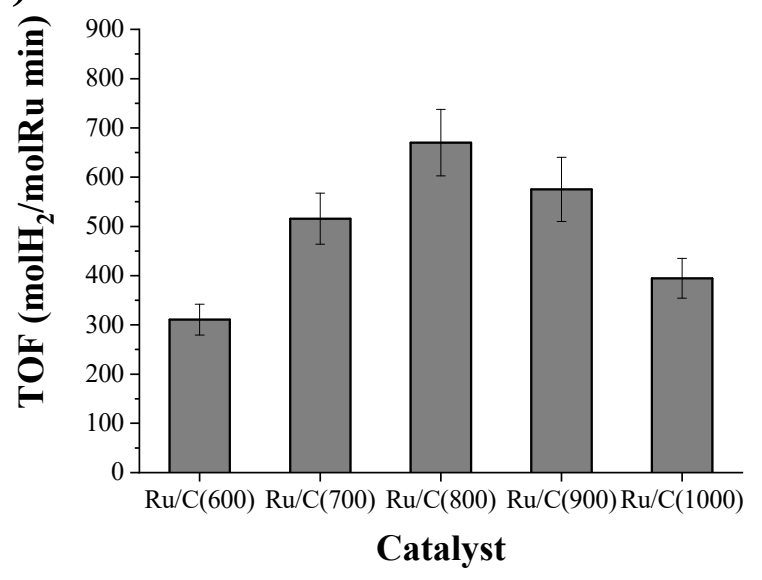

Figure 3. (a) Catalytic activity of the Ru-based catalysts in the $\mathrm{AB}$ hydrolysis reaction at $30^{\circ} \mathrm{C}$. (b) Turnover frequency (TOF) number $\left(\mathrm{mol}_{\mathrm{H} 2} \cdot \mathrm{mol}_{\mathrm{Ru}}{ }^{-1} \cdot \mathrm{min}^{-1}\right)$ calculated at $\mathrm{t}=5.5 \mathrm{~min}$ for the $\mathrm{Ru} / \mathrm{C}$ samples prepared by Ru complex decomposition. The average TOF numbers were calculated after performing three different catalytic tests. Adapted with permission from [79].

Gao et al. [70] studied the performance of Ru/nanodiamonds in the hydrolytic dehydrogenation of AB. That study was motivated by a wide variety of oxygen functional groups present in the nanodiamonds, which were expected to serve as anchoring points for the Ru NPs. Commercial nanodiamonds, with an average diameter of 5-10 nm were used as the support and $\mathrm{RuCl}_{3}$ as the metal precursor, for the synthesis of catalysts with a metal content of $3.22,4.82,6.21$, and $8.05 \mathrm{wt}$. \%. The TOF values showed a volcano-type tendency, the best catalyst being that with a Ru content of $6.21 \mathrm{wt} . \%\left(229 \mathrm{~mol}_{\mathrm{H} 2} \cdot \mathrm{mol}_{\mathrm{Ru}}{ }^{-1} \cdot \mathrm{min}^{-1}\right)$. The recyclability tests performed with that sample indicated that total conversion of $A B$ was achieved during four consecutive runs, but the TOF values decreased during the cycles, which was related to the increase of the NPs from 3.7 to $5.1 \mathrm{~nm}$ and the increasing viscosity and concentration of metaborate in the reaction solution.

Most of the catalysts used for the hydrolytic dehydrogenation of $\mathrm{AB}$ displayed good reusability and attained total conversion during several consecutive reaction runs. However, the reaction is frequently sluggish and longer reaction times are needed to produce 3 equivalents of $\mathrm{H}_{2}$ per mole of $\mathrm{AB}$, so the poor stability of the catalysts under reaction conditions is one of the most addressed issues.

The stability of the catalysts was shown to improve upon utilization of supports with abundant surface functional groups, which are known to increase the stability and reusability of the catalysts [8]. That was the case of Fan et al., who developed catalysts consisting of ultrafine and highly dispersed Ru NPs supported on N-doped carbon nanosheets formed by a hierarchically porous carbon material (HPCM) [76]. Ru/HPCM had an average NP size of $1.41 \mathrm{~nm}$ and narrow size distribution, which ranged from $0.6 \mathrm{~nm}$ to $2.0 \mathrm{~nm}$. Such ultrafine NPs were confined into the micropores and mesopores of the support, affording numerous active sites and stabilizing the NPs from sintering under reaction conditions. X-ray Photoelectron Spectroscopy (XPS) analysis confirmed the presence of pyridinic, pyrrolic, and graphitic nitrogen. The importance of both pyridinic and graphitic nitrogen in enhancing catalytic performance was pointed out in that study. Ru/HPCM was evaluated during eight consecutive reaction cycles, after which it retained $50 \%$ of its initial activity. After that, the average NP size of the spent catalyst slightly increased to $1.47 \mathrm{~nm}$ and the partial activity decay was related to the catalyst loss and the passivation effect of metaborate ions formed along the recycling tests. The same group also synthesized Rubased catalysts supported on N-doped bagasse-derived carbon materials (BC-hs) [73]. That 
biomass residue, which has abundant negative oxygen and nitrogen functional groups, was suitable for the interaction with $\mathrm{Ru}^{3+}$ cations of the metal precursor. Catalysts with various metal contents (i.e., 2.5, 3.5, 4.5, and $5.5 \mathrm{wt}$. \%) were synthesized by in-situ reduction with $\mathrm{AB}$, achieving homogeneously dispersed ultrafine Ru NPs. It was observed that the best-performing catalyst preserved $80 \%$ of its TOF value after five runs, demonstrating the suitability of the BC-hs support to stabilize the metal NPs. The partial loss of the activity was attributed to changes in the NP size and loss of the catalyst during the separation and washing steps.

Ma et al. used a support based on a N-doped porous carbon material (NC-Fe) using a facile pyrolysis of a porous organic polymer (POP) synthesized from ferrocene carboxaldehyde and melamine as the starting materials [69]. The resulting $\mathrm{Ru}$ catalyst ( $\mathrm{Ru} / \mathrm{NC}-\mathrm{Fe})$ achieved the total conversion of $\mathrm{AB}$ during five cycles, but the reaction was considerably sluggish. That catalyst contained $\gamma-\mathrm{Fe}_{2} \mathrm{O}_{3}$, so it was easily recovered with a magnet. The activity decay was attributed to both the metaborate formed in the reaction and the agglomeration of the metal NPs.

Liu et al. used a N-enriched hierarchically macroporous-mesoporous carbon support that was synthesized by a co-template evaporation-induced self-assembly approach with $\mathrm{SiO}_{2}$ nanospheres as a macroporous hard template and $\mathrm{F} 127$ as a mesoporous soft template and a soft nitriding by the low-temperature thermolysis of urea [99]. The resulting support, denoted as hPCN, was loaded with Ru NPs (Ru@hPCN), and reference catalysts based on pure macroporous and pure mesoporous support were also prepared (Ru@macroPCN and Ru@mesoPCN, respectively). Ru@hPCN exhibited the best activity and total dehydrogenation was finished in $120 \mathrm{~s}$, while longer reaction times were required for the reference samples and for a commercial Ru/C catalyst (160, 280, and 880 s, for Ru@macroPCN, $\mathrm{Ru} @$ mesoPCN, and Ru/C, respectively). Such better performance of Ru@hPCN was also evidenced by the higher TOF values achieved at $60{ }^{\circ} \mathrm{C}\left(1850,1258,902\right.$, and $308 \mathrm{~min}^{-1}$, for Ru@hPCN, Ru@macroPCN,Ru@mesoPCN, and Ru/C, respectively). The reusability of Ru@hPCN was evaluated during four consecutive reaction cycles and it was observed that the NP size increased from $0.7 \mathrm{~nm}$ to $2.7 \mathrm{~nm}$. Additionally, the amount of surface $\mathrm{N}$ species decreased from 13.4 at. \% to 2.3 at. \%, which suggested that the N-enriched species contributed to improving the catalytic performance by dissociating the electropositive $\mathrm{H}^{\delta+}$ from water molecules and the breakage of the B-N bonds.

Not only N-doped carbon materials, but also other N-containing carbon-based supports were shown to be effective in stabilizing Ru NPs for the hydrolytic dehydrogenation of AB. For instance, Zheng et al. used hierarchical porous graphitic carbon nitride $\left(g-\mathrm{C}_{3} \mathrm{~N}_{4}\right)$ nanosheets to anchor ultrafine Ru NPs [100]. In that case, the supports were prepared from melamine and various amounts of $\mathrm{NH}_{4} \mathrm{Cl}$ as a dynamic gas template. The NPs were encapsulated into the network of the $g-\mathrm{C}_{3} \mathrm{~N}_{4}$ by the reduction of the metal precursor with $\mathrm{NaBH}_{4}$ to achieve a final metal content of $1.91 \mathrm{wt}$. \%. The characterization of the catalyst indicated that the resulting NPs had a size that ranged from 1.9 to $5.1 \mathrm{~nm}$ and they exhibited uniform dispersion onto the support. Among the synthesized supports, that prepared with a melamine to $\mathrm{NH}_{4} \mathrm{Cl}$ mass ratio of 1:3 exhibited the highest surface area $\left(\mathrm{S}_{\mathrm{BET}}\right.$ of $59 \mathrm{~m}^{2} \mathrm{~g}^{-1}$ ) and its counterpart Ru catalyst was selected to assess the performance in the dehydrogenation of $\mathrm{AB}$. That catalyst displayed satisfactory recyclability even after four consecutive reaction cycles. The activity loss observed from the fifth cycle was attributed to a particle aggregation of the NPs and to the accumulation of $\mathrm{NH}_{4} \mathrm{BO}_{2}$ species in the reaction solution, which increases its viscosity and blocks the active sites of the catalyst.

Tang et al. also explored the suitability of $\mathrm{Ru} / \mathrm{g}-\mathrm{C}_{3} \mathrm{~N}_{4}$ catalysts for the dehydrogenation of $\mathrm{AB}$ [77]. In that case, the catalysts were prepared from urea and $\mathrm{RuCl}_{3}$. Catalysts with various metal loadings (i.e., $4.10,3.28,2.46$, and $1.64 \mathrm{wt}$. \%) were synthesized. The time needed for the reaction to be completed decreased to $3.5 \mathrm{~min}$ for the catalyst with 3.28 wt. $\%$, which showed the highest TOF value $\left(459.3 \mathrm{~mol}_{\mathrm{H} 2} \cdot \mathrm{mol}_{\mathrm{Ru}}{ }^{-1} \cdot \mathrm{min}^{-1}\right)$. Concerning the recyclability of $\mathrm{Ru} / \mathrm{g}-\mathrm{C}_{3} \mathrm{~N}_{4}$, it preserved $50 \%$ of the initial catalytic activity after 
the fourth run, and the activity loss was related to the increase of the size of the NPs from $2.8 \mathrm{~nm}$ to $4.1 \mathrm{~nm}$ and the adsorption of B species on the surface of the NPs.

Yamashita et al. also studied the performance of $g-C_{3} N_{4}$ supported Ru catalysts [101]. In that case, carbon $/ g-\mathrm{C}_{3} \mathrm{~N}_{4}$ composites with various carbon contents $\left(\mathrm{C}(\mathrm{x}) / g-\mathrm{C}_{3} \mathrm{~N}_{4} ;{ }^{\prime \prime} \mathrm{x}\right.$ " is the initial carbon weight per cent of $0.1,0.5,1.0,2.0$, and $4.0 \mathrm{wt}$. \%, respectively) were synthesized from glucose and dicyandiamide by a simple experimental procedure. The obtained supports were subsequently impregnated with $\mathrm{RuCl}_{3} \cdot 3 \mathrm{H}_{2} \mathrm{O}$ to obtain $\mathrm{Ru} \mathrm{NPs}$ after reduction with $\mathrm{H}_{2}$ gas at $300{ }^{\circ} \mathrm{C}$. The incorporation of carbon was reported to extend the absorption of the materials to the visible region of $480-800 \mathrm{~nm}$ compared to the pristine $g-\mathrm{C}_{3} \mathrm{~N}_{4}$, so the resulting $\mathrm{Ru} / \mathrm{C}(\mathrm{x}) / \mathrm{g}-\mathrm{C}_{3} \mathrm{~N}_{4}$ were interesting photocatalysts for the dehydrogenation of $\mathrm{AB}$ under visible-light irradiation. Additionally, the incorporation of carbon served to achieve smaller Ru NPs than those achieved in the raw $g-C_{3} \mathrm{~N}_{4}$, which also affected the catalytic activity. Figure 4 contains information on the catalytic activity displayed by $\mathrm{Ru} / \mathrm{C}(\mathrm{x}) / g-\mathrm{C}_{3} \mathrm{~N}_{4}$. It was observed that the addition of moderated carbon contents in the catalysts enhanced the activity compared to that displayed by $\mathrm{Ru} / \mathrm{g}-\mathrm{C}_{3} \mathrm{~N}_{4}$, which was related to the smaller NPs shown in those samples (Figure 4a). It was also seen that the reaction rate of all the materials improved under visible light irradiation (Figure $4 \mathrm{~b}$ ), achieving the fastest reaction rate with $\mathrm{Ru} / \mathrm{C}(1.0) / g-\mathrm{C}_{3} \mathrm{~N}_{4}$.
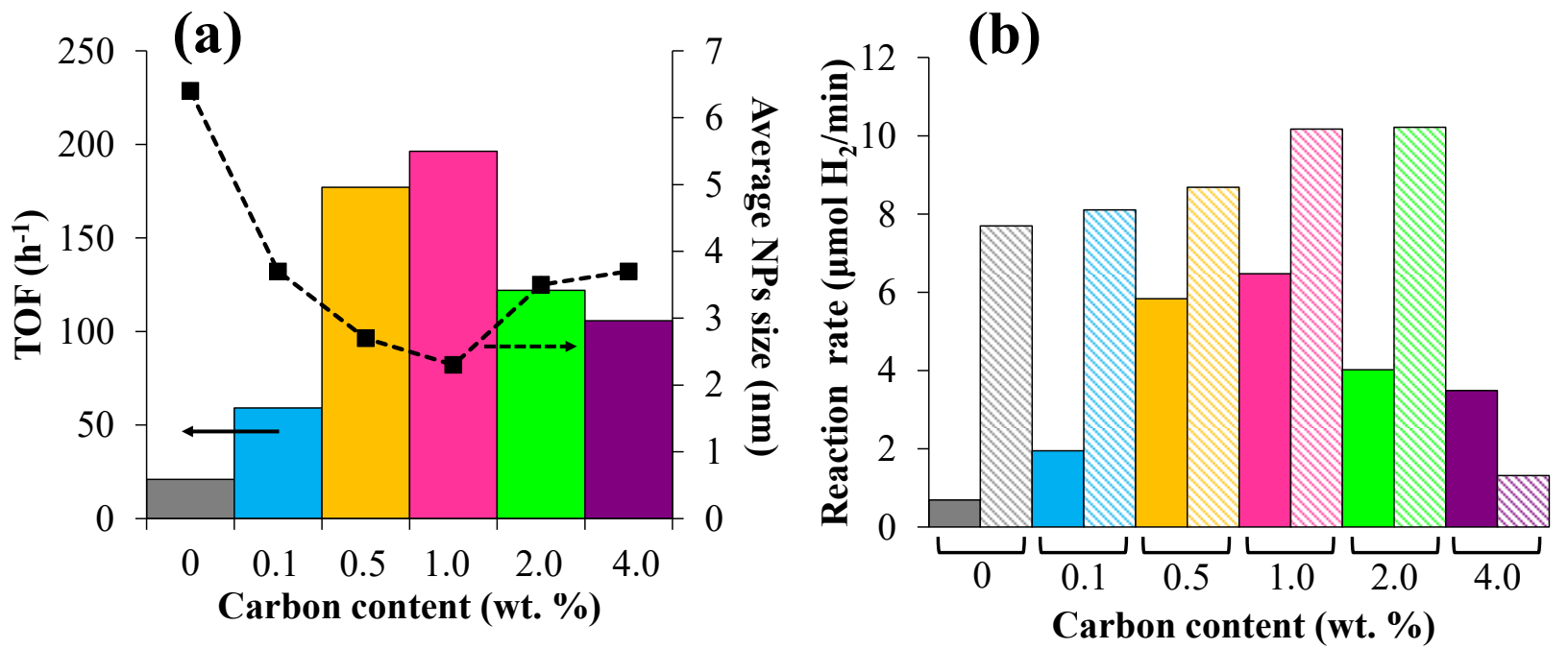

Figure 4. (a) TOF $\left(\mathrm{h}^{-1}\right)$ for $\mathrm{Ru} / \mathrm{C}(\mathrm{x}) / g-\mathrm{C}_{3} \mathrm{~N}_{4}$ as a function of the carbon content and average Ru NP size. (b) Initial reaction rate for the dehydrogenation of $\mathrm{AB}$ as a function of the carbon content under dark conditions (solid bars) and visible light irradiation (hollow bars). Adapted from [101].

Interesting results were also achieved by Fan et al., who synthesized phosphorusdoped carbon-supported Ru catalysts (Ru/PPC) [74]. In that study, the supports were prepared from hypercrosslinked polymer networks of triphenylphosphine and benzene, and they were subsequently used for the synthesis of Ru catalysts with various metal contents (i.e., 1.5, 2.5, 3.5, and 4.5 wt. \%). Small and well-distributed Ru NPs were attained in all the materials, the smallest for Ru/PPC with $3.5 \mathrm{wt}$. \% of Ru (average size of $1.13 \mathrm{~nm}$ ). The catalytic activity was shown to be dependent on the metal content, achieving TOF values of $174,325,413$, and $290 \mathrm{~mol}_{\mathrm{H} 2} \cdot \mathrm{mol}_{\mathrm{Ru}}{ }^{-1} \cdot \mathrm{min}^{-1}$ for catalysts with $1.5,2.5,3.5$, and $4.5 \mathrm{wt}$. \% of Ru, respectively. The stability of the most active material was evaluated during four consecutive cycles, observing that its activity gradually decreased after the first run. Such loss of activity was attributed to the NP sintering (from 1.13 to $2.47 \mathrm{~nm}$ ) as well as the catalyst loss in the separation and washing steps.

\section{Hydrolytic Dehydrogenation of AB over Oxide-Supported Catalysts}

As in most catalytic reactions, carbon materials are the most fruitfully studied supports. However, interesting results have also been achieved with oxide-supported catalysts, with 
silica $\left(\mathrm{SiO}_{2}\right)$ and alumina $\left(\mathrm{Al}_{2} \mathrm{O}_{3}\right)$ the most investigated. Representative examples of such systems are summarized in this section.

$\mathrm{SiO}_{2}$ has been shown to serve as a suitable support for the dehydrogenation of $\mathrm{AB}$. $\mathrm{SiO}_{2}$, with various structures and morphologies, have been nicely utilized for the development of well-performing catalysts. For instance, Zhu et al. reported on Ru NPs confined in SBA-15 (Ru@SBA-15) by using a double solvent approach (with hexane and water) [85]. Metal loadings of $0.5,1.1,2.1,3.2$, and $4.0 \mathrm{wt}$. \% were used, which resulted in NPs with an average size of $2.0 \pm 0.6 \mathrm{~nm}, 2.2 \pm 0.6 \mathrm{~nm}, 3.0 \pm 0.8 \mathrm{~nm}$, and $3.7 \pm 0.7 \mathrm{~nm}$, respectively. Among investigated, Ru@SBA-15 with a metal content of $2.1 \mathrm{wt}$. \% displayed the best activity, which was also superior to those catalysts with non-confined NPs supported on SBA-15 and $\mathrm{SiO}_{2}$. It also showed good durability after five consecutive reaction runs at room temperature.

Chen et al. designed Ru catalysts supported on cubic 3D cage-type mesoporous silica SBA-1 functionalized with carboxylic acid (Ru/S1B-C10) [84]. The carboxylic acid was incorporated by co-condensation of tetraethyl orthosilicate (TEOS) and carboxyethylsilanetriol sodium salt in the presence of poly(acrylic acid) and hexadecylpyridinium chloride. The $-\mathrm{COOH}$ groups were uniformly distributed within the mesopores of the support, which assisted the preparation of well-dispersed and small Ru NPs. Catalysts with metal loadings from 0.5 to $2.0 \mathrm{wt}$. \% were synthesized with both - $\mathrm{COOH}$ free support (SIB-C0) and $-\mathrm{COOH}$ containing support (S1B-C10). It was observed that while the average NP size observed in $\mathrm{Ru} / \mathrm{S} 1 \mathrm{~B}-\mathrm{C} 0$ catalysts increased from 2.8 to $4.6 \mathrm{~nm}$ when the metal loading increased from 0.5 to $2.0 \mathrm{wt}$. \%, it only increased from 2.0 to $3.2 \mathrm{~nm}$ in Ru/SIB-C10 for similar metal contents. Catalysts with $1 \mathrm{wt}$. \% of Ru displayed better performance for both SIB-C0 and SIB-C10 supports than materials with other Ru loadings. Among those investigated, $\mathrm{Ru}(1) @ S 1 B-C 10$ had the highest TOF value $\left(202 \mathrm{~mol}_{\mathrm{H} 2} \cdot \mathrm{mol}_{\mathrm{Ru}}{ }^{-1} \cdot \mathrm{min}^{-1}\right)$, which was attributed to the nanosized Ru particles and their good dispersion as well as the effect of the pore confinement of the support. The reusability of the best-performing catalysts was evaluated during five reaction cycles and even though the total conversion was achieved in all cases, the reaction rates decreased with an increase in the number of cycling tests, which was related to a partial metal leaching and restricted access of reactants to the Ru active sites originated by the adsorption of metaborate on the surface of the NPs.

Yao el at. prepared core-shell $\mathrm{Ru} @ \mathrm{SiO}_{2}$ catalysts with various metal contents (i.e., 1.0, 2.0, 3.0, 4.0, 6.0, 8.0, and 10.0 wt. \%), which consisted of Ru NPs of $\sim 2 \mathrm{~nm}$ embedded in the center of spherical $\mathrm{SiO}_{2}$ particles of $\sim 25 \mathrm{~nm}$ [83]. Among those investigated, ${\mathrm{Ru} @ S i O_{2}}$ with $6 \mathrm{wt}$. \% of $\mathrm{Ru}$ loading exhibited the best performance for the production of $\mathrm{H}_{2}$ from $\mathrm{AB}$, with a TOF of $200 \mathrm{~mol}_{\mathrm{H} 2} \cdot \mathrm{mol}_{\mathrm{Ru}}{ }^{-1} \cdot \mathrm{min}^{-1}$. A much slower reaction rate was observed for a supported $\mathrm{Ru} / \mathrm{SiO}_{2}$ catalyst used as a reference sample, which was related to the easy aggregation occurring in $\mathrm{Ru} / \mathrm{SiO}_{2}$. The $\mathrm{Ru} @ \mathrm{SiO}_{2}$ core-shell catalyst displayed good recycling stability for five cycles, but the reaction was progressively sluggish during the cycles.

Özkar et al. explored the activity of catalysts formed by Ru NPs loaded on magnetic silica-coated cobalt ferrite $\left(\mathrm{Ru}(0) / \mathrm{SiO}_{2}-\mathrm{CoFe}_{2} \mathrm{O}_{4}\right)$ [82]. That catalyst showed a moderated activity, with a TOF of $172 \mathrm{~mol}_{\mathrm{H} 2} \cdot \mathrm{mol}_{\mathrm{Ru}}{ }^{-1} \cdot \mathrm{min}^{-1}$ at room temperature, but excellent recyclability during 10 reaction runs, preserving $94 \%$ of the initial activity. After each reaction cycle, the spent catalyst was isolated using a permanent magnet, and no metal leaching was detected.

Onat et al. [86] also developed $\mathrm{SiO}_{2}$-based magnetic core-shell catalysts. In that study, $\mathrm{Ru}$ NPs were loaded on amino functionalized silica-covered magnetic NPs $\left(\mathrm{Fe}_{3} \mathrm{O}_{4} @ \mathrm{SiO}_{2}-\right.$ $\mathrm{NH}_{2}-\mathrm{Ru}$ ), and the resulting catalysts were evaluated in the dehydrogenation of $\mathrm{AB}$. It was claimed that the amine group served to increase the electron transfer from the coreshell $\mathrm{Fe}_{3} \mathrm{O}_{4} @ \mathrm{SiO}_{2}$ structure to the surface of the Ru NPs, which resulted in enhanced catalytic activity in the production of $\mathrm{H}_{2}$. The developed catalyst had a TOF value of $617 \mathrm{~mol}_{\mathrm{H} 2} \cdot \mathrm{mol}_{\mathrm{cat}}{ }^{-1} \cdot \mathrm{min}^{-1}$ and showed good stability during eight reaction cycles. 
$\mathrm{Al}_{2} \mathrm{O}_{3}$ has also been applied for the synthesis of Ru-based catalysts for the dehydrogenation of AB. For instance, Metin el al. reported an easy method for the synthesis of nearly monodisperse Ru NPs, which consisted in the thermal decomposition and simultaneous reduction of the metal precursor (ruthenium(III) acetylacetonate $\left(\mathrm{Ru}(\mathrm{acac})_{3}\right)$ in the presence of oleylamine (serving as a stabilizer and reducing agent) and benzylether (used as solvent) [87]. The as-synthesized NPs (with an average size of $2.5 \mathrm{~nm}$ ) were subsequently loaded on $\gamma-\mathrm{Al}_{2} \mathrm{O}_{3}$ to build a $\mathrm{Ru} @ \mathrm{Al}_{2} \mathrm{O}_{3}$ catalyst with $1 \mathrm{wt}$. \% of $\mathrm{Ru}$. That material had a TOF of $39.6 \mathrm{~mol}_{\mathrm{H} 2} \cdot \mathrm{mol}_{\mathrm{Ru}}{ }^{-1} \cdot \mathrm{min}^{-1}$. It was observed that the TOF value increased to $83.3 \mathrm{~mol} \mathrm{~mol}_{\mathrm{H} 2} \cdot \mathrm{mol}_{\mathrm{Ru}}{ }^{-1}$ after carrying out a treatment of the catalyst with acetic acid, which removed the organics from the surface of the NPs. The treated catalysts exhibited great stability even after 10 consecutive reaction runs, and the TOF only decreased $10 \%$ of the initial value.

Chen el at. developed a microporous crystalline $\gamma-\mathrm{Al}_{2} \mathrm{O}_{3}$ with a large surface area (large surface, $349 \mathrm{~m}^{2} \mathrm{~g}^{-1}$ ) prepared from a microporous covalent triazine framework (CTF-1, surface area of $697 \mathrm{~m}^{2} \mathrm{~g}^{-1}$ ) as a template [88]. Ru-based catalysts with 1, 2, and $5 \mathrm{wt}$. \% were prepared from $\mathrm{RuCl}_{3}$ and they were evaluated in the dehydrogenation of $\mathrm{AB}$. The high surface area and the hierarchical pore structures of the micropores developed in the synthesized $\gamma-\mathrm{Al}_{2} \mathrm{O}_{3}$ was claimed to be responsible for the better performance achieved by the materials studied in that work compared to those reported elsewhere for $\mathrm{Ru} / \gamma-\mathrm{Al}_{2} \mathrm{O}_{3}$ catalysts (TOF as high as $256.8 \mathrm{~mol}_{\mathrm{H} 2} \cdot \mathrm{mol}_{\mathrm{Ru}}{ }^{-1} \cdot \mathrm{min}^{-1}$ was obtained for $\mathrm{Ru} / \gamma-\mathrm{Al}_{2} \mathrm{O}_{3}$ with 2 wt. \%; while values of one order of magnitude lower were attained for $\mathrm{Ru} / \gamma-\mathrm{Al}_{2} \mathrm{O}_{3}$ reported in other studies).

Fan et al. evaluated the performance of catalysts formed by Ru NPs supported on $\mathrm{Al}_{2} \mathrm{O}_{3}$ nanofibers with an average length of 200-300 nm and a BET surface area of $300 \mathrm{~m}^{2} \mathrm{~g}^{-1}$ $\left(\mathrm{Ru} / \mathrm{Al}_{2} \mathrm{O}_{3}-\mathrm{NFs}\right)$ [89]. Catalysts with metal contents from 2.52 to $4.91 \mathrm{wt}$. \% were prepared in-situ by reducing the metal precursor with $\mathrm{AB}$. It was observed that the time needed to achieve a total conversion of $\mathrm{AB}$ decreased with increasing the metal content. The stability test indicated that $\mathrm{AB}$ conversion was completed even during five consecutive runs, but the reaction rate decreased along the cycles, which was attributed to an increase of the average NPs size from 2.9 to $3.1 \mathrm{~nm}$.

Lee et al. investigated the effect of the crystal phase of Ru on the dehydrogenation of $\mathrm{AB}$ by using face-centered cubic (fcc) structures and hexagonal close-packed (hcp) structured Ru NPs loaded on $\gamma-\mathrm{Al}_{2} \mathrm{O}_{3}$ [102]. Catalysts with $1 \mathrm{wt}$. \% of Ru and different sizes of both fcc and hcp Ru NPs were prepared. The size and the crystal phase were controlled by adjusting the experimental conditions, in terms of amount and type of metal precursor, solvent, and amount of PVP. It was observed that under the experimental conditions used in that study, fcc NPs were achieved using $\mathrm{Ru}(\mathrm{acac})_{3}$ while $\mathrm{RuCl}_{3}$ originated hcp NPs. XPS analysis suggested that fcc Ru NPs were more easily oxidized than the hcp counterpart since a larger relative proportion of $\mathrm{Ru}^{4+}$ was detected (i.e., $\left[\mathrm{Ru}^{4+}\right] /\left[\mathrm{Ru}^{0}\right]$ of 28.2 and $19.2 \%$ for fcc and hcp Ru/ $\gamma-\mathrm{Al}_{2} \mathrm{O}_{3}$, respectively). The catalytic activity of fcc and hcp NPs with different sizes (i.e., 2.4, 3.5, 3.9, and $5.4 \mathrm{~nm}$ ) was evaluated by monitoring the $\mathrm{H}_{2}$ generation profiles at $25{ }^{\circ} \mathrm{C}$ (see Figure 5). As can be seen, hcp NPs displayed better performance regardless of the size of the NPs. It was also seen that the difference between hcp and fcc NPs became smaller as the NPs increased. Additionally, the opposite tendency was seen for fcc and hcp NPs: the catalytic activity of fcc $\mathrm{Ru} / \gamma-\mathrm{Al}_{2} \mathrm{O}_{3}$ enhanced with increasing NP size, while hcp displayed worse performance with increasing sizes. Density functional theory (DFT) calculations were done to determine the adsorption energy of $\mathrm{O}_{2}$ molecules on the (001) crystal plane of fcc and hcp Ru to get information about their easy oxidation. The results obtained suggest that the fcc Ru was easily oxidized than hcp Ru, which was consistent with the experimental results observed in that study. Thus, the authors of that study ascribed the worse performance of smaller NPs with fcc crystal phases to their higher degree of oxidation, while the tendency observed for hcp was attributed to size effects. 

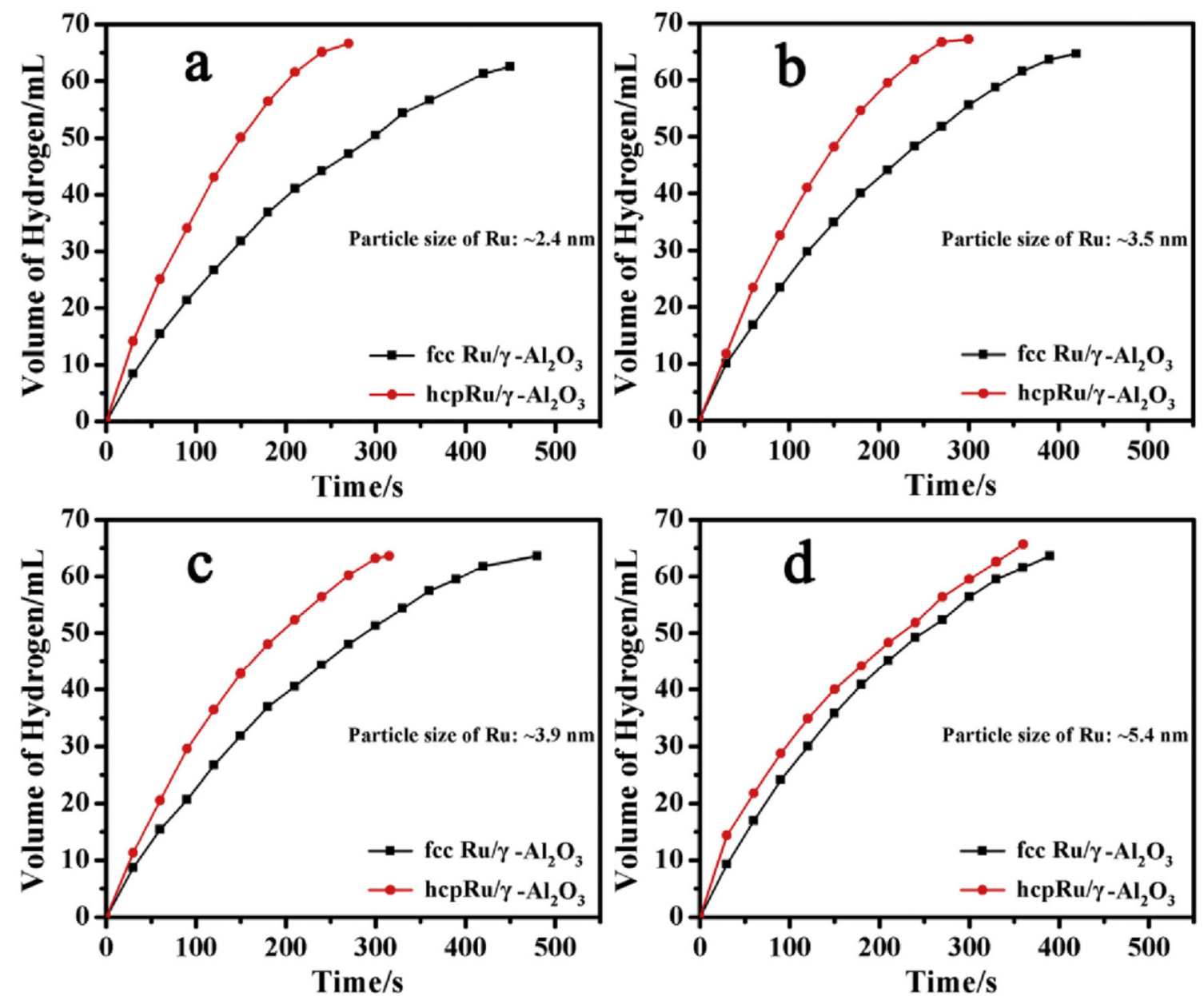

Figure 5. The plot of $\mathrm{H}_{2}$ volume (mL) versus time (s) graph for the dehydrogenation of $\mathrm{AB}\left(\mathrm{n}_{\mathrm{AB}}=1 \mathrm{mmol}\right)$ catalyzed by the Ru with different crystal phase (fcc: face-centered cubic; hcp: hexagonal close-packed) for different particle sizes: (a) $\sim 2.4 \mathrm{~nm},(\mathbf{b}) \sim 3.5 \mathrm{~nm},(\mathbf{c}) \sim 3.9 \mathrm{~nm}$, (d) $\sim 5.4 \mathrm{~nm}$. Experimental conditions: $25^{\circ} \mathrm{C}$ and $\mathrm{n}_{\mathrm{Ru}} / \mathrm{n}_{\mathrm{AB}}=0.003$. Adapted from [102].

Some examples of the use of other oxides such as titania $\left(\mathrm{TiO}_{2}\right)[90,103]$, ceria $\left(\mathrm{CeO}_{2}\right)[104,105]$, and hafnia $\left(\mathrm{HfO}_{2}\right)$ [91] as catalytic supports of $\mathrm{Ru}$ NPs for the hydrolytic dehydrogenation of $\mathrm{AB}$ can also be found in the literature.

\section{Other Supported Ru Catalysts}

Carbon materials and oxides are the most investigated supports for the hydrolytic dehydrogenation of $\mathrm{AB}$, but there are other interesting materials that have also attracted great interest in the last years. Among them, the utilization of MOF should be highlighted because of the attention drawn not only for this application, but for many other catalytic reactions [106-108]. They have been shown to be suitable to embed metal NPs as well as to stabilize them by incorporating additional functionalization. This was the case of Chen et al., who achieved well-dispersed Ru NPs immobilized within the pores of amine-functionalized MIL-53 by using an in-situ impregnation-reduction method [94]. It was claimed that the amino groups were located at the acid linkers in MIL-53(Al)- $\mathrm{NH}_{2}$, and served as Lewis bases, thus stabilizing the $\mathrm{Ru}$ precursor (i.e., $\mathrm{RuCl}_{3}$ ) during the impregnation step. An amino-free catalyst was prepared for comparison purposes. The average NP size was determined to be $1.22 \mathrm{~nm}$, smaller than the mean diameter of the pores of the amino functionalized MIL-53(Al) $(2.07 \mathrm{~nm})$ so that they were embedded in the framework of the MOF, while larger NPs were located on the external surface. Ru/MIL53(Al)- $\mathrm{NH}_{2}$ catalyst displayed better activity than the amino-free counterpart, and also better durability and reusability. Such better performance exhibited by Ru/MIL-53(Al)$\mathrm{NH}_{2}$ was attributed to the amino groups, which assisted the formation and stabilization 
of small Ru NPs. Xia et al. also used MIL-53 as support of Ru NPs for the hydrolytic dehydrogenation of AB. In that study, Ru NPs were deposited on MIL-53(Cr) and MIL53(Al) by the impregnation method with $\mathrm{RuCl}_{3}$. Catalysts with Ru contents of $0.19,0.67$, 1.61 , and 2.65 wt. \% were obtained for Ru@MIL-53(Cr), and metal contents of $0.12,0.74$, $1.95,2.59$ wt. \% were achieved for Ru@MIL-53(Al). Among the samples assessed, 2.65 wt. \% Ru@MIL-53(Cr) and $2.59 \mathrm{wt} \% \mathrm{Ru} @ \mathrm{MIL}-53(\mathrm{Al})$ displayed the best performance, with TOF values of 260.8 and $266.9 \mathrm{~mol}_{\mathrm{H} 2} \cdot \mathrm{mol}_{\mathrm{Ru}}{ }^{-1} \cdot \mathrm{min}^{-1}$, respectively. Those catalysts also showed good stability, preserving $71 \%$ and $75 \%$ of the initial catalytic activity of Ru@MIL-53(Cr) and 2.59 wt. \% Ru@ MIL-53(Al) after the fifth run, respectively. Chen et al. prepared catalysts formed by ultrasmall Ru NPs supported on MIL-96 (Ru/MIL-96) [92]. The MOF selected in that study was claimed to be a 3D framework with three different kind of cages as well as with thermal and chemical stability in water. Ru catalysts loaded on other supports (i.e., carbon black, $\mathrm{SiO}_{2}, \gamma-\mathrm{Al}_{2} \mathrm{O}_{3}$, and $\mathrm{GO}$ ) were prepared for comparison purposes. Ru/MIL-96 was the most active catalysts checked in that study, with a TOF of $231 \mathrm{~mol}_{\mathrm{H} 2} \cdot \mathrm{mol}_{\mathrm{Ru}}{ }^{-1} \cdot \mathrm{min}^{-1}$. However, that material did not show suitable stability, since it only retained $65 \%$ of its initial activity after the fifth run, which was attributed to the increasing NP size and viscosity of the solution.

Zhu et al. explored the suitability of a N-containing microporous organic framework (POF) as a scaffold to anchor Ru NPs [95]. The resulting catalyst, which was denoted as $\mathrm{Ru} / \mathrm{PAF}-72$, has an average NP size of $1-2 \mathrm{~nm}$ and showed a TOF of $294 \mathrm{~mol}_{\mathrm{H} 2} \cdot \mathrm{mol}_{\mathrm{Ru}}{ }^{-1} \cdot \mathrm{min}^{-1}$. The most remarkable aspect of that system was its great stability even after 10 consecutive reaction cycles. For comparison purposes, the stability of a catalyst based on Ru NPs loaded onto carbon black was also evaluated, showing a significant activity decay after only four cycles.

Additionally, some other supports, which are less frequently used in catalysts, have served to develop Ru catalysts for the hydrolytic dehydrogenation of AB. For instance, Cai et al. developed a sophisticated catalyst based on Ru NPs loaded a natural polyphenolic polymer (bayberry tannin, BT) immobilized on collagen fibers (CF). The catalysts, denoted as CF-BT-Ru, were synthesized by immobilization of BT, crosslinking of glutaraldehyde, and subsequent chelation of $\mathrm{Ru}^{3+}$ (final metal loadings of $0.58,1.03,1.57$, and 2.12 wt. \%) [71]. The procedure used is shown in Figure 6. Various reference samples were also prepared for comparison purposes (i.e., CF-BT-Ru, CF-Ru, and Ru-carbon material (Ac, GO, CNTs and $\left.g-\mathrm{C}_{3} \mathrm{~N}_{4}\right)$ ). It was observed that the presence of BT enhanced the dispersion of the metal active phase, due to the interaction with the phenolic groups, so that the BT containing catalyst has much smaller Ru NPs than the BT-free counterpart (i.e., $2.6 \pm 0.6$ and $6.5 \pm 0.5 \mathrm{~nm}$, respectively). XPS characterization indicated that the catalyst contained positively charged nitrogen and neutral amine groups. Such neutral amine groups were responsible for the stabilization of the Ru NPs by providing some of their electrons. The six catalysts evaluated showed total conversion of $\mathrm{AB}$, but different reaction rates, with CF-BT-Ru being the most active with a TOF of $322 \mathrm{~mol}_{\mathrm{H} 2} \cdot \mathrm{mol}_{\mathrm{Ru}}{ }^{-1} \cdot \mathrm{min}^{-1}$.

In an attempt to gain insights into the less explored effect of the composition of the support, Zhao et al. [96] selected a material that consisted of composition-adjustable layered double hydroxide (MgAl-LDHs) as support for Ru NPs. The general formula of the selected support is $\left[\mathrm{M}^{2+}{ }_{1-\mathrm{x}} \mathrm{M}^{3+}{ }_{\mathrm{x}}(\mathrm{OH})_{2}\right]^{\mathrm{x}+}\left[\mathrm{A}^{\mathrm{n}-}\right]_{\mathrm{x} / \mathrm{n}} \cdot \mathrm{yH}_{2} \mathrm{O}$, where $\mathrm{M}^{2+}$ and $\mathrm{M}^{3+}$ are cations, and $\mathrm{A}^{\mathrm{n}-}$ is the charge balancing anion. In that study, supports with different compositions of MgAl-LDHs were synthesized by urea hydrolysis (supports denoted as $\mathrm{Mg}_{2} \mathrm{Al}-\mathrm{LDH}-\mathrm{h}, \mathrm{Mg}_{3} \mathrm{Al}-\mathrm{LDH}-\mathrm{h}$, and $\mathrm{Mg}_{4} \mathrm{Al}-\mathrm{LDH}-\mathrm{h}$ ). $\mathrm{Mg}_{4} \mathrm{Al}-\mathrm{LDH}$ was also prepared from a co-precipitation method (support denoted as $\mathrm{Mg}_{4} \mathrm{Al}-\mathrm{LDH}-\mathrm{p}$ ). After that, Ru catalysts were prepared from $\mathrm{RuCl}_{3} \cdot \mathrm{H}_{2} \mathrm{O}$. The results of the catalytic activity indicated that the activity followed the order $\mathrm{Ru} / \mathrm{Mg}_{2} \mathrm{Al}-\mathrm{LDH}-\mathrm{h}>\mathrm{Ru} / \mathrm{Mg}_{3} \mathrm{Al}-\mathrm{LDH}-\mathrm{h}>\mathrm{Ru} / \mathrm{Mg}_{4} \mathrm{Al}-\mathrm{LDH}-(\mathrm{h})$ $>\mathrm{Ru} / \mathrm{Mg}_{4} \mathrm{Al}-\mathrm{LDH}-(\mathrm{p})$, with TOF values of $85.7,63.3,42.7$, and $40.1 \mathrm{~mol}_{\mathrm{H} 2} \cdot \mathrm{mol}_{\mathrm{Ru}}{ }^{-1} \cdot \mathrm{min}^{-1}$, respectively. According to that observation, it was postulated that the $\mathrm{Mg} / \mathrm{Al}$ ratio, which is related to the relative acidity of the material and the support-Ru interaction, was a key aspect in controlling the final catalytic performance. It was found that $\mathrm{Ru} / \mathrm{Mg}_{2} \mathrm{Al}-$ LDH-h had more Brønsted acid sites and it showed a weaker interaction with Ru species, 
which enabled the existence of $\mathrm{Ru}$ in the metallic state, thus explaining the better activity exhibited by that catalyst. That sample preserved its stability during the first four cycles, but it slightly decayed from the fourth to the tenth consecutive run, which was attributed to the increased viscosity of the solution, which impedes the diffusion of $\mathrm{AB}$ molecules, thus hindering their interaction with the Ru active sites.

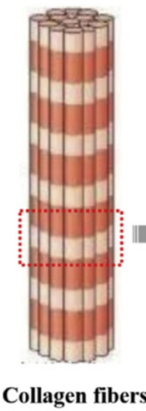

(a)

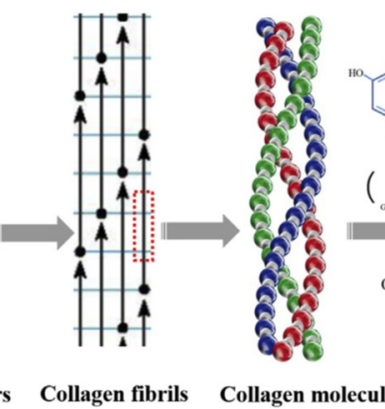

(b)

(c)

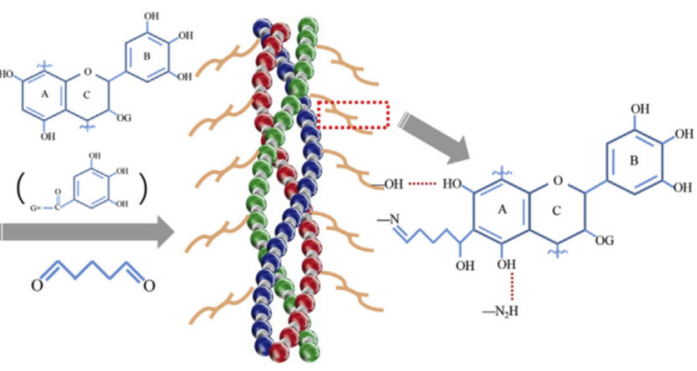

Immobilization of BT and crosslinking of glutaraldehyde

(d)

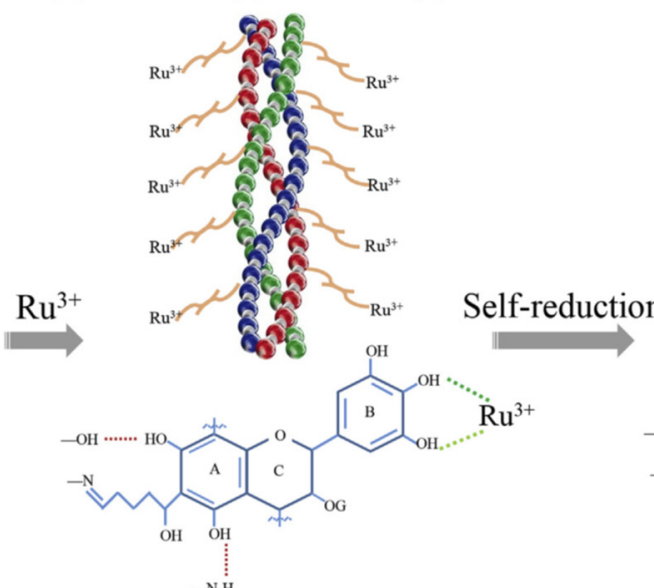

(e)

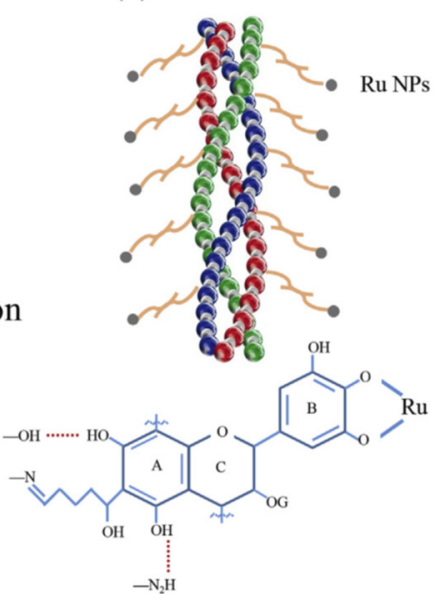

(f)

Figure 6. Diagram of (a) collagen fibers, (b) collagen fibrils, (c) collagen molecules, (d) immobilization of bayberry tannin (BT), and crosslinking of glutaraldehyde, (e) chelation of $\mathrm{Ru}^{3+}$ ions with phenolic hydroxyl groups, and (f) formation of Ru NPs under self-reduction. Reprinted with permission from [71].

Sun et al. also explored the performance of MgAl-LDH-supported Ru catalysts for the hydrolytic dehydrogenation of $\mathrm{AB}$ [97]. In this case, supports with a composition of $\mathrm{Mg}_{0.5} \mathrm{Al}_{1}-\mathrm{LDHs}, \mathrm{Mg}_{1} \mathrm{Al}_{1}$-LDHs, $\mathrm{Mg}_{2} \mathrm{Al}_{1}-\mathrm{LDHs}$, and $\mathrm{Mg}_{3} \mathrm{Al}_{1}-\mathrm{LDH}$ were prepared and loaded with $\mathrm{Ru}$ NPs. Among those samples, $\mathrm{Ru} / \mathrm{Mg}_{1} \mathrm{Al}_{1}$-LDHs showed better activity, completing the hydrogen release in $130 \mathrm{~s}$, compared to the other catalysts that needed longer reaction times $\left(180,140\right.$, and $230 \mathrm{~s}$, for $\mathrm{Ru} / \mathrm{Mg}_{0.5} \mathrm{Al}_{1}-\mathrm{LDHs}, \mathrm{Ru} / \mathrm{Mg}_{2} \mathrm{Al}_{1}-\mathrm{LDHs}$, and $\mathrm{Ru} / \mathrm{Mg}_{3} \mathrm{Al}_{1}$-LDHs). In this case, such tendency was also attributed not only to the higher content of Brønsted acid sites in $\mathrm{Ru} / \mathrm{Mg}_{1} \mathrm{Al}_{1}-\mathrm{LDHs}$, but also to the higher purity of $\mathrm{Mg}_{1} \mathrm{Al}_{1}$-LDHs, which did not contain boehmite $(\mathrm{AlO}(\mathrm{OH}))$ and hydromagnesite $\left(\mathrm{Mg}_{5}\left(-\mathrm{CO}_{3}\right)_{4}(\mathrm{OH})_{2} \cdot 4 \mathrm{H}_{2} \mathrm{O}\right) \cdot \mathrm{Ru} / \mathrm{Mg}_{1} \mathrm{Al}_{1}-\mathrm{LDH}$ exhibited good stability during 10 reaction runs, and $58.1 \%$ of the initial activity remained after those cycles. DTF calculations were conducted to get information on the promotion effect of MgAl-LDHs catalysts. It was determined that $\mathrm{Ru} / \mathrm{MgAl}-\mathrm{LDH}$ catalysts have the beneficial electronic properties to accelerate the $\mathrm{H}_{2} \mathrm{O}$ dissociation to form $\mathrm{O}-\mathrm{H}$ bonds, activating the $\mathrm{H}_{2} \mathrm{O}$ molecules during the hydrolytic dehydrogenation of $\mathrm{AB}$.

\section{Conclusions and Perspectives}

There is great hope for the potential of hydrogen as an energy vector, which motivates the search for alternatives that overcome the limitations that are frequently related to 
its storage. Chemical hydrogen storage stands up as a promising option and there are several hydrogen carrier molecules that afford satisfactory hydrogen capacity. Among them, ammonia borane has drawn much attention, and research to exploit the potential of ammonia borane as a hydrogen storage material has been intensified in the last years.

This review summarized some of the recent Ru-based heterogeneous catalysts applied in the hydrolytic dehydrogenation of ammonia borane. A perusal of the most frequently used catalysts is included, paying particular attention to those heterogeneous catalysts with carbon materials and oxides as supports. Among the vast diversity of supported Ru catalysts studied thus far, carbon material-based catalysts frequently attain the best performance.

Most of the investigations deal with the optimization of the properties of the active phase such as the nanoparticle size and morphology, while the effect of the composition of the support is less explored. Most of the catalysts experienced deactivation during few consecutive reaction cycles, which is linked to several factors: (i) aggregation of the nanoparticles; (ii) metal leaching; and (iii) accumulation of metaborate in the solution and change in the viscosity. It is expected that such phenomena involved in the deactivation of the catalysts could be partially averted by using encapsulated or nanoconfined metal catalysts upon selection of a suitable porous material serving as a host for the metal active phase. Most studies include information about the NP size and metal content of the spent catalysts, but no information has been reported about the concentration of metaborate species and viscosity of the solution before and after the reaction, which would help to verify such possible reasons for deactivation that are frequently mentioned but never confirmed. Some other interesting works evidenced the formation of different B-containing products such as $\mathrm{B}(\mathrm{OH})_{3}, \mathrm{BO}_{2}{ }^{-}, \mathrm{B}(\mathrm{OH})_{4}{ }^{-}$, and polyborates [64,65,109-111].

Some studies have aimed at enhancing the cyclability of the catalysts by stabilizing the metallic phases using strong metal-support interaction, using, for example, a support with abundant functional groups. Nitrogen-containing supports have been widely studied, but the resulting catalysts are still lacking in stability during the cycles. Hence, the insufficient stability of the assessed catalysts is frequently the weakest point indicated in the literature for the heterogeneous catalysts used in the dehydrogenation of ammonia borane. The regeneration of the catalysts after reaction would therefore be a very interesting issue to be considered in future works.

No attention is paid to the actual cornerstone for the successful application of this hydrogen carrier molecule in the hydrogen storage scenario, which is the regeneration of ammonia borane from the products obtained in its decomposition reaction. The $A B$ regeneration problem, which was pointed out long back [112], remains unsolved nowadays and studies dealing with the regeneration of $A B$ are still sparse [113]. The nature of the by-products of the hydrolysis of $\mathrm{AB}$, which are mainly borate species, complicates the regeneration of $\mathrm{AB}$, since the stable $\mathrm{B}-\mathrm{O}$ bond formed in the by-product are strong and they are not easily reconverted to the $\mathrm{B}-\mathrm{H}$ bond present in $\mathrm{AB}$ molecules, so a strong reducing agent would be needed. Thus, multi-step reactions are required for the regeneration of $A B$. For instance, Liu et al. proposed a regeneration process that implied the conversion of boric acid to trimethyl borate $\left(\mathrm{B}\left(\mathrm{OCH}_{3}\right)_{3}\right.$ by esterification with methanol. Then, $\mathrm{B}\left(\mathrm{OCH}_{3}\right)_{3}$ can react with $\mathrm{NaH}$, generating $\mathrm{NaBH}_{4}$ and, finally, $\mathrm{AB}$ was formed upon reaction of $\mathrm{NaH}$ with ammonia sulfate in THF [114]. Gagare et al. aimed at regenerating $\mathrm{AB}$ from $\mathrm{NH}_{4} \mathrm{~B}(\mathrm{OMe})_{4}$ using $\mathrm{LiAlH}_{4}$ as a reducing agent and $\mathrm{NH}_{4} \mathrm{Cl}$ as an ammonia source [115]. Vasiliu et al. reported on the regeneration of $\mathrm{AB}$ from a more simplified and energy-efficient process that involved minimum reaction steps [116]. However, their starting point was not the regeneration of the by-products originating from the production of 3 equivalents of $\mathrm{H}_{2}$ per molecule of $\mathrm{AB}$, but polyborazylene was used, which is formed upon generation of two equivalents of $\mathrm{H}_{2}$ per molecule of $\mathrm{AB}$ (partially spent $\mathrm{AB}$ ). In that case, polyborazylene was converted to $\mathrm{AB}$ nearly quantitatively by $24 \mathrm{~h}$ treatment with $\mathrm{N}_{2} \mathrm{H}_{4}$ in liquid $\mathrm{NH}_{3}$ at $40{ }^{\circ} \mathrm{C}$. More recently, Sharma et al. [117] studied the regeneration of $\mathrm{AB}$ using a digestion-based approach in the presence of methanol and subsequent regeneration with the reducing agent (i.e., $\mathrm{LiAlH}_{4}$ ). 
There is still plenty of room for improvement in both the design and development of stable and reusable catalysts as well as in the processes involved in the real application of ammonia borane as a hydrogen storage material, especially for those on-board systems. One of the main issues to be tackled is the high cost of ammonia borane compared to other hydrogen storage systems, so finding cost-effective ways for the synthesis and regeneration of ammonia borane is highly desirable.

The present review contains only information on monometallic Ru-based catalysts, which have been shown to be the most effective to attain suitable catalytic behavior, but there are other compositions that have also displayed interesting results.

Author Contributions: M.N.-G. designed the structure of the review and wrote the manuscript; D.S.-T. contributed to the writing of the manuscript; and D.C.-A. reviewed the paper. All authors have read and agreed to the published version of the manuscript.

Funding: This work was financed by the MICINN, FEDER (RTI2018-095291-B-I00). MNG thanks the Plan GenT project (CDEIGENT/2018/027) for their financial support. DST thanks MICINN for the "Juan de la Cierva" contract (IJCI-2016-27636) and the Vicerrectorado de Investigación y Transferencia de Conocimiento de la Universidad de Alicante (GRE19-16).

Institutional Review Board Statement: Not applicable.

Informed Consent Statement: Not applicable.

Data Availability Statement: Data sharing not applicable.

Conflicts of Interest: The authors declare no conflict of interest.

\section{References}

1. Zheng, J.; Zhou, H.; Wang, C.-G.; Ye, E.; Xu, J.W.; Loh, X.J.; Li, Z. Current research progress and perspectives on liquid hydrogen rich molecules in sustainable hydrogen storage. Energy Storage Mater. 2021, 35, 695-722. [CrossRef]

2. McGee, M. Available online: https:/ / www.co2.earth/ (accessed on 12 March 2021).

3. Mazloomi, K.; Gomes, C. Hydrogen as an energy carrier: Prospects and challenges. Renew. Sustain. Energy Rev. 2012, 16, 3024-3033. [CrossRef]

4. Abdin, Z.; Zafaranloo, A.; Rafiee, A.; Mérida, W.; Lipiński, W.; Khalilpour, K.R. Hydrogen as an energy vector. Renew. Sustain. Energy Rev. 2020, 120, 109620. [CrossRef]

5. Navlani-García, M.; Mori, K.; Kuwahara, Y.; Yamashita, H. Recent strategies targeting efficient hydrogen production from chemical hydrogen storage materials over carbon-supported catalysts. NPG Asia Mater. 2018, 10, 1-16. [CrossRef]

6. Lai, Q.; Sun, Y.; Wang, T.; Modi, P.; Cazorla, C.; Demirci, U.B.; Ares Fernandez, J.R.; Leardini, F.; Aguey-Zinsou, K.-F. How to Design Hydrogen Storage Materials? Fundamentals, Synthesis, and Storage Tanks. Adv. Sustain. Syst. 2019, 3, 1900043. [CrossRef]

7. Zhang, F.; Zhao, P.; Niu, M.; Maddy, J. The survey of key technologies in hydrogen energy storage. Int. J. Hydrogen Energy 2016, 41, 14535-14552. [CrossRef]

8. Salinas-Torres, D.; Navlani-García, M.; Mori, K.; Kuwahara, Y.; Yamashita, H. Nitrogen-doped carbon materials as a promising platform toward the efficient catalysis for hydrogen generation. Appl. Catal. A Gen. 2019, 571, 25-41. [CrossRef]

9. U.S. Department of Energy. Available online: https://www.energy.gov/eere/fuelcells/doe-technical-targets-onboard-hydrogenstorage-light-duty-vehicles (accessed on 12 March 2021).

10. Berenguer-Murcia, Á.; Marco-Lozar, J.P.; Cazorla-Amorós, D. Hydrogen Storage in Porous Materials: Status, Milestones, and Challenges. Chem. Rec. 2018, 18, 900-912. [CrossRef]

11. Schlapbach, L.; Züttel, A. Hydrogen-storage materials for mobile applications. Nature 2001, 414, 353-358. [CrossRef] [PubMed]

12. Demirci, U.B.; Miele, P. Chemical hydrogen storage: “Material" gravimetric capacity versus "system" gravimetric capacity. Energy Environ. Sci. 2011, 4, 3334-3341. [CrossRef]

13. Rivard, E.; Trudeau, M.; Zaghib, K. Hydrogen storage for mobility: A review. Materials 2019, 12, 1973. [CrossRef]

14. Dalebrook, A.F.; Gan, W.; Grasemann, M.; Moret, S.; Laurenczy, G. Hydrogen storage: Beyond conventional methods. Chem. Commun. 2013, 49, 8735-8751. [CrossRef] [PubMed]

15. Yüksel Alpaydın, C.; Gülbay, S.K.; Ozgur Colpan, C. A review on the catalysts used for hydrogen production from ammonia borane. Int. J. Hydrogen Energy 2020, 45, 3414-3434. [CrossRef]

16. Demirci, U.B. Ammonia borane: An extensively studied, though not yet implemented, hydrogen carrier. Energies 2020, $13,3071$. [CrossRef]

17. Li, C.; Peng, P.; Zhou, D.W.; Wan, L. Research progress in $\mathrm{LiBH}_{4}$ for hydrogen storage: A review. Int. J. Hydrogen Energy 2011, 36, 14512-14526. [CrossRef]

18. Luo, Y.; Sun, L.; Xu, F.; Liu, Z. Improved hydrogen storage of $\mathrm{LiBH}_{4}$ and $\mathrm{NH}_{3} \mathrm{BH}_{3}$ by catalysts. J. Mater. Chem. A 2018, 6, 7293-7309. [CrossRef] 
19. Liu, B.H.; Li, Z.P. A review: Hydrogen generation from borohydride hydrolysis reaction. J. Power Sources 2009, 187, 527-534. [CrossRef]

20. Abdelhamid, H.N. A review on hydrogen generation from the hydrolysis of sodium borohydride. Int. J. Hydrogen Energy 2021, 46, 726-765. [CrossRef]

21. Sun, Z.; Lu, X.; Nyahuma, F.M.; Yan, N.; Xiao, J.; Su, S.; Zhang, L. Enhancing Hydrogen Storage Properties of $\mathrm{MgH}_{2}$ by Transition Metals and Carbon Materials: A Brief Review. Front. Chem. 2020, 8, 552. [CrossRef]

22. Perejón, A.; Sánchez-Jiménez, P.E.; Criado, J.M.; Pérez-Maqueda, L.A. Magnesium hydride for energy storage applications: The kinetics of dehydrogenation under different working conditions. J. Alloys Compd. 2016, 681, 571-579. [CrossRef]

23. Lamb, K.E.; Dolan, M.D.; Kennedy, D.F. Ammonia for hydrogen storage; A review of catalytic ammonia decomposition and hydrogen separation and purification. Int. J. Hydrogen Energy 2019, 44, 3580-3593. [CrossRef]

24. Aziz, M.; TriWijayanta, A.; Nandiyanto, A.B.D. Ammonia as effective hydrogen storage: A review on production, storage and utilization. Energies 2020, 13, 3062. [CrossRef]

25. Palo, D.R.; Dagle, R.A.; Holladay, J.D. Methanol Steam Reforming for Hydrogen Production. Chem. Rev. 2007, $107,3992-4021$. [CrossRef]

26. Onishi, N.; Laurenczy, G.; Beller, M.; Himeda, Y. Recent progress for reversible homogeneous catalytic hydrogen storage in formic acid and in methanol. Coord. Chem. Rev. 2018, 373, 317-332. [CrossRef]

27. Cheng, Y.; $\mathrm{Wu}, \mathrm{X} . ; \mathrm{Xu}, \mathrm{H}$. Catalytic decomposition of hydrous hydrazine for hydrogen production. Sustain. Energy Fuels 2019, 3, 343-365. [CrossRef]

28. Zhou, L.; Luo, X.; Xu, L.; Wan, C.; Ye, M. Pt-ni nanoalloys for $\mathrm{H}_{2}$ generation from hydrous hydrazine. Catalysts 2020, 10, 930. [CrossRef]

29. Joy, J.; Mathew, J.; George, S.C. Nanomaterials for photoelectrochemical water splitting-Review. Int. J. Hydrogen Energy 2018, 43, 4804-4817. [CrossRef]

30. Fajrina, N.; Tahir, M. A critical review in strategies to improve photocatalytic water splitting towards hydrogen production. Int. J. Hydrogen Energy 2019, 44, 540-577. [CrossRef]

31. Navlani-García, M.; Salinas-Torres, D.; Mori, K.; Kuwahara, Y.; Yamashita, H. Photocatalytic Approaches for Hydrogen Production via Formic Acid Decomposition. Top. Curr. Chem. 2019, 377, 27. [CrossRef]

32. Navlani-García, M.; Mori, K.; Salinas-Torres, D.; Kuwahara, Y.; Yamashita, H. New Approaches Toward the Hydrogen Production From Formic Acid Dehydrogenation Over Pd-Based Heterogeneous Catalysts. Front. Mater. 2019, 6, 44. [CrossRef]

33. Navlani-García, M.; Salinas-Torres, D.; Cazorla-Amorós, D. Hydrogen production from formic acid attained by bimetallic heterogeneous pdag catalytic systems. Energies 2019, 12, 4027. [CrossRef]

34. Srinivasan, S.; Demirocak, D.E.; Kaushik, A.; Sharma, M.; Chaudhary, G.R.; Hickman, N.; Stefanakos, E. Reversible hydrogen storage using nanocomposites. Appl. Sci. 2020, 10, 4618. [CrossRef]

35. Qin, G.; Cui, Q.; Yun, B.; Sun, L.; Du, A.; Sun, Q. High capacity and reversible hydrogen storage on two dimensional $\mathrm{C}_{2} \mathrm{~N}$ monolayer membrane. Int. J. Hydrogen Energy 2018, 43, 9895-9901. [CrossRef]

36. Cao, Z.; Ouyang, L.; Wang, H.; Liu, J.; Felderhoff, M.; Zhu, M. Reversible hydrogen storage in yttrium aluminum hydride. J. Mater. Chem. A 2017, 5, 6042-6046. [CrossRef]

37. Zhang, C. Hydrogen storage: Improving reversibility. Nat. Energy 2017, 2, 17064. [CrossRef]

38. Staubitz, A.; Robertson, A.P.M.; Manners, I. Ammonia-Borane and Related Compounds as Dihydrogen Sources. Chem. Rev. 2010, 110, 4079-4124. [CrossRef]

39. Kumar, R.; Karkamkar, A.; Bowden, M.; Autrey, T. Solid-state hydrogen rich boron-nitrogen compounds for energy storage. Chem. Soc. Rev. 2019, 48, 5350-5380. [CrossRef]

40. Marder, T.B. Will We Soon Be Fueling our Automobiles with Ammonia-Borane? Angew. Chem. Int. Ed. 2007, 46, 8116-8118. [CrossRef]

41. Shore, S.G.; Parry, R.W. The Crystalline Compound Ammonia-Borane, ${ }^{1} \mathrm{H}_{3} \mathrm{NBH}_{3}$. J. Am. Chem. Soc. 1955, 77, 6084-6085. [CrossRef]

42. Valero-Pedraza, M.-J.; Cot, D.; Petit, E.; Aguey-Zinsou, K.-F.; Alauzun, J.G.; Demirci, U.B. Ammonia Borane Nanospheres for Hydrogen Storage. ACS Appl. Nano Mater. 2019, 2, 1129-1138. [CrossRef]

43. Stephens, F.H.; Pons, V.; Tom Baker, R. Ammonia-borane: The hydrogen source par excellence? Dalt. Trans. 2007, 2613-2626. [CrossRef]

44. Zhan, W.W.; Zhu, Q.L.; Xu, Q. Dehydrogenation of Ammonia Borane by Metal Nanoparticle Catalysts. ACS Catal. 2016, 6, 6892-6905. [CrossRef]

45. Green, I.G.; Johnson, K.M.; Roberts, B.P. Homolytic reactions of ligated boranes. Part 13. An electron spin resonance study of radical addition to aminoboranes. J. Chem. Soc. Perkin Trans. 1989, 2, 1963-1972. [CrossRef]

46. Cheng, H.; Kamegawa, T.; Mori, K.; Yamashita, H. Surfactant-Free Nonaqueous Synthesis of Plasmonic Molybdenum Oxide Nanosheets with Enhanced Catalytic Activity for Hydrogen Generation from Ammonia Borane under Visible Light. Angezw. Chemie Int. Ed. 2014, 53, 2910-2914. [CrossRef]

47. Verma, P.; Kuwahara, Y.; Mori, K.; Yamashita, H. Enhancement of Ag-based plasmonic photocatalysis in hydrogen production from ammonia borane by the assistance of single-site Ti-oxide moieties within a silica framework. Chem. A Eur. J. 2017, 23, 3616-3622. [CrossRef] 
48. Wen, M.; Cui, Y.; Kuwahara, Y.; Mori, K.; Yamashita, H. Non-Noble-Metal Nanoparticle Supported on Metal-Organic Framework as an Efficient and Durable Catalyst for Promoting $\mathrm{H}_{2}$ Production from Ammonia Borane under Visible Light Irradiation. ACS Appl. Mater. Interfaces 2016, 8, 21278-21284. [CrossRef]

49. Yin, H.; Kuwahara, Y.; Mori, K.; Yamashita, H. Plasmonic metal/MoxW $\mathrm{M}_{1-\mathrm{x}} \mathrm{O}_{3-\mathrm{y}}$ for visible-light-enhanced $\mathrm{H}_{2}$ production from ammonia borane. J. Mater. Chem. A 2018, 6, 10932-10938. [CrossRef]

50. Masuda, S.; Mori, K.; Sano, T.; Miyawaki, K.; Chiang, W.-H.; Yamashita, H. Simple Route for the Synthesis of Highly Active Bimetallic Nanoparticle Catalysts with Immiscible $\mathrm{Ru}$ and $\mathrm{Ni}$ Combination by utilizing a $\mathrm{TiO}_{2}$ Support. ChemCatChem 2018, 10, 3526-3531. [CrossRef]

51. Fernández-Catalá, J.; Navlani-García, M.; Verma, P.; Berenguer-Murcia, Á.; Mori, K.; Kuwahara, Y.; Yamashita, H.; CazorlaAmorós, D. Photocatalytically-driven $\mathrm{H}_{2}$ production over $\mathrm{Cu} / \mathrm{TiO}_{2}$ catalysts decorated with multi-walled carbon nanotubes. Catal. Today 2021, 364, 182-189. [CrossRef]

52. Salinas-Torres, D.; Navlani-García, M.; Kuwahara, Y.; Mori, K.; Yamashita, H. Non-noble metal doped perovskite as a promising catalyst for ammonia borane dehydrogenation. Catal. Today 2019, 351, 6-11. [CrossRef]

53. García-Aguilar, J.; Navlani-García, M.; Berenguer-Murcia, Á.; Mori, K.; Kuwahara, Y.; Yamashita, H.; Cazorla-Amorós, D. Enhanced ammonia-borane decomposition by synergistic catalysis using CoPd nanoparticles supported on titano-silicates. RSC Adv. 2016, 6, 91768-91772. [CrossRef]

54. Liu, P.-H.; Wen, M.; Tan, C.-S.; Navlani-García, M.; Kuwahara, Y.; Mori, K.; Yamashita, H.; Chen, L.-J. Surface plasmon resonance enhancement of production of $\mathrm{H} 2$ from ammonia borane solution with tunable $\mathrm{Cu}_{2}-\mathrm{xS}$ nanowires decorated by $\mathrm{Pd}$ nanoparticles. Nano Energy 2017, 31, 57-63. [CrossRef]

55. Akbayrak, S.; Özkar, S. Ammonia Borane as Hydrogen Storage Materials. Int. J. Hydrogen Energy 2018, 43, 18592-18606. [CrossRef]

56. Akbayrak, S.; Tonbul, Y.; Özkar, S. Magnetically Separable $\mathrm{Rh}^{0} / \mathrm{Co}_{3} \mathrm{O}_{4}$ Nanocatalyst Provides over a Million Turnovers in Hydrogen Release from Ammonia Borane. ACS Sustain. Chem. Eng. 2020, 8, 4216-4224. [CrossRef]

57. Akbayrak, S.; Çakmak, G.; Öztürk, T.; Özkar, S. Rhodium(0), Ruthenium(0) and Palladium(0) nanoparticles supported on carbon-coated iron: Magnetically isolable and reusable catalysts for hydrolytic dehydrogenation of ammonia borane. Int. J. Hydrogen Energy 2020, 46, 13548-13560. [CrossRef]

58. Tonbul, Y.; Akbayrak, S.; Özkar, S. Nanozirconia supported ruthenium(0) nanoparticles: Highly active and reusable catalyst in hydrolytic dehydrogenation of ammonia borane. J. Colloid Interface Sci. 2018, 513, 287-294. [CrossRef] [PubMed]

59. Jiang, H.-L.; Xu, Q. Catalytic hydrolysis of ammonia borane for chemical hydrogen storage. Catal. Today 2011, 170, 56-63. [CrossRef]

60. Umegaki, T.; Yabuuchi, K.; Yoshida, N.; Xu, Q.; Kojima, Y. In situ synthesized hollow spheres of a silica-ruthenium-nickel composite catalyst for the hydrolytic dehydrogenation of ammonia borane. New J. Chem. 2019, 44, 450-455. [CrossRef]

61. Chen, Y.; Yang, X.; Kitta, M.; Xu, Q. Monodispersed Pt nanoparticles on reduced graphene oxide by a non-noble metal sacrificial approach for hydrolytic dehydrogenation of ammonia borane. Nano Res. 2017, 10, 3811-3816. [CrossRef]

62. Li, J.; Zhu, Q.L.; Xu, Q. Non-noble bimetallic CuCo nanoparticles encapsulated in the pores of metal-organic frameworks: Synergetic catalysis in the hydrolysis of ammonia borane for hydrogen generation. Catal. Sci. Technol. 2015, 5, 525-530. [CrossRef]

63. Liu, M.; Zhou, L.; Luo, X.; Wan, C.; Xu, L. Recent advances in noble metal catalysts for hydrogen production from ammonia borane. Catalysts 2020, 10, 788. [CrossRef]

64. Chen, W.; Li, D.; Wang, Z.; Qian, G.; Sui, Z.; Duan, X.; Zhou, X.; Yeboah, I.; Chen, D. Reaction mechanism and kinetics for hydrolytic dehydrogenation of ammonia borane on a Pt/CNT catalyst. AIChE J. 2017, 63, 60-65. [CrossRef]

65. Xu, Q.; Chandra, M. Catalytic activities of non-noble metals for hydrogen generation from aqueous ammonia-borane at room temperature. J. Power Sources 2006, 163, 364-370. [CrossRef]

66. Peng, C.-Y.; Kang, L.; Cao, S.; Chen, Y.; Lin, Z.-S.; Fu, W.-F. Nanostructured Ni2P as a Robust Catalyst for the Hydrolytic Dehydrogenation of Ammonia-Borane. Angew. Chem. Int. Ed. 2015, 54, 15725-15729. [CrossRef]

67. Ma, H.; Na, C. Isokinetic temperature and size-controlled activation of ruthenium-catalyzed ammonia borane hydrolysis. ACS Catal. 2015, 5, 1726-1735. [CrossRef]

68. Cao, N.; Luo, W.; Cheng, G. One-step synthesis of graphene supported Ru nanoparticles as efficient catalysts for hydrolytic dehydrogenation of ammonia borane. Int. J. Hydrogen Energy 2013, 38, 11964-11972. [CrossRef]

69. Cui, Z.; Guo, Y.; Feng, Z.; Xu, D.; Ma, J. Ruthenium nanoparticles supported on nitrogen-doped porous carbon as a highly efficient catalyst for hydrogen evolution from ammonia borane. New J. Chem. 2019, 43, 4377-4384. [CrossRef]

70. Fan, G.; Liu, Q.; Tang, D.; Li, X.; Bi, J.; Gao, D. Nanodiamond supported Ru nanoparticles as an effective catalyst for hydrogen evolution from hydrolysis of ammonia borane. Int. J. Hydrogen Energy 2016, 41, 1542-1549. [CrossRef]

71. Fu, L.; Cai, L. Ru nanoparticles loaded on tannin immobilized collagen fibers for catalytic hydrolysis of ammonia borane. Int. J. Hydrogen Energy 2021, 46, 10749-10762. [CrossRef]

72. Akbayrak, S.; Özkar, S. Ruthenium(0) nanoparticles supported on multiwalled carbon nanotube as highly active catalyst for hydrogen generation from ammonia-borane. ACS Appl. Mater. Interfaces 2012, 4, 6302-6310. [CrossRef]

73. Cheng, W.; Zhao, X.; Luo, W.; Zhang, Y.; Wang, Y.; Fan, G. Bagasse-derived Carbon-supported Ru nanoparticles as Catalyst for Efficient Dehydrogenation of Ammonia Borane. ChemNanoMat 2020, 6, 1251-1259. [CrossRef] 
74. Lu, R.; Xu, C.; Wang, Q.; Wang, Y.; Zhang, Y.; Gao, D.; Bi, J.; Fan, G. Ruthenium nanoclusters distributed on phosphorus-doped carbon derived from hypercrosslinked polymer networks for highly efficient hydrolysis of ammonia-borane. Int. J. Hydrogen Energy 2018, 43, 18253-18260. [CrossRef]

75. Liang, H.; Chen, G.; Desinan, S.; Rosei, R.; Rosei, F.; Ma, D. In situ facile synthesis of ruthenium nanocluster catalyst supported on carbon black for hydrogen generation from the hydrolysis of ammonia-borane. Int. J. Hydrogen Energy 2012, 37, 17921-17927. [CrossRef]

76. Zhong, F.; Wang, Q.; Xu, C.; Yang, Y.; Wang, Y.; Zhang, Y.; Gao, D.; Bi, J.; Fan, G. Ultrafine and highly dispersed Ru nanoparticles supported on nitrogen-doped carbon nanosheets: Efficient catalysts for ammonia borane hydrolysis. Appl. Surf. Sci. 2018, 455, 326-332. [CrossRef]

77. Fan, Y.; Li, X.; He, X.; Zeng, C.; Fan, G.; Liu, Q.; Tang, D. Effective hydrolysis of ammonia borane catalyzed by ruthenium nanoparticles immobilized on graphic carbon nitride. Int. J. Hydrogen Energy 2014, 39, 19982-19989. [CrossRef]

78. Du, C.; Ao, Q.; Cao, N.; Yang, L.; Luo, W.; Cheng, G. Facile synthesis of monodisperse ruthenium nanoparticles supported on graphene for hydrogen generation from hydrolysis of ammonia borane. Int. J. Hydrogen Energy 2015, 40, 6180-6187. [CrossRef]

79. Navlani-García, M.; Mori, K.; Nozaki, A.; Kuwahara, Y.; Yamashita, H. Highly efficient Ru/carbon catalysts prepared by pyrolysis of supported $\mathrm{Ru}$ complex towards the hydrogen production from ammonia borane. Appl. Catal. A Gen. 2016, 527, 45-52. [CrossRef]

80. Chu, H.; Li, N.; Qiu, X.; Wang, Y.; Qiu, S.; Zeng, J.-L.; Zou, Y.; Xu, F.; Sun, L. Poly(N-vinyl-2-pyrrolidone)-stabilized ruthenium supported on bamboo leaf-derived porous carbon for NH3BH3 hydrolysis. Int. J. Hydrogen Energy 2019, 44, $29255-29262$. [CrossRef]

81. Chu, H.; Li, N.; Qiu, S.; Zou, Y.; Xiang, C.; Xu, F.; Sun, L. Ruthenium supported on nitrogen-doped porous carbon for catalytic hydrogen generation from NH3BH3 hydrolysis. Int. J. Hydrogen Energy 2019, 44, 1774-1781. [CrossRef]

82. Akbayrak, S.; Kaya, M.; Volkan, M.; Özkar, S. Ruthenium(0) nanoparticles supported on magnetic silica coated cobalt ferrite: Reusable catalyst in hydrogen generation from the hydrolysis of ammonia-borane. J. Mol. Catal. A Chem. 2014, 394, $253-261$. [CrossRef]

83. Yao, Q.; Shi, W.; Feng, G.; Lu, Z.-H.; Zhang, X.; Tao, D.; Kong, D.; Chen, X. Ultrafine Ru nanoparticles embedded in SiO 2 nanospheres: Highly efficient catalysts for hydrolytic dehydrogenation of ammonia borane. J. Power Sources 2014, 257, 293-299. [CrossRef]

84. Deka, J.R.; Saikia, D.; Hsia, K.S.; Kao, H.M.; Yang, Y.C.; Chen, C.S. Ru nanoparticles embedded in cubic mesoporous silica SBA-1 as highly efficient catalysts for hydrogen generation from ammonia borane. Catalysts 2020, 10, 267. [CrossRef]

85. Yao, Q.; Lu, Z.-H.; Yang, K.; Chen, X.; Zhu, M. Ruthenium nanoparticles confined in SBA-15 as highly efficient catalyst for hydrolytic dehydrogenation of ammonia borane and hydrazine borane. Sci. Rep. 2015, 5, 15186. [CrossRef] [PubMed]

86. Sait Izgi, M.; Ece, M.Ş.; Kazici, H.Ç.; Şahin, Ö.; Onat, E. Hydrogen production by using Ru nanoparticle decorated with $\mathrm{Fe}_{3} \mathrm{O}_{4} @ \mathrm{SiO}_{2}-\mathrm{NH}_{2}$ core-shell microspheres. Int. J. Hydrogen Energy 2020, 45, 30415-30430. [CrossRef]

87. Can, H.; Metin, Ö. A facile synthesis of nearly monodisperse ruthenium nanoparticles and their catalysis in the hydrolytic dehydrogenation of ammonia borane for chemical hydrogen storage. Appl. Catal. B Environ. 2012, 125, 304-310. [CrossRef]

88. Zhang, M.; Liu, L.; He, T.; Li, Z.; Wu, G.; Chen, P. Microporous Crystalline $\gamma-\mathrm{Al}_{2} \mathrm{O}_{3}$ Replicated from Microporous Covalent Triazine Framework and Its Application as Support for Catalytic Hydrolysis of Ammonia Borane. Chem. Asian J. 2017, 12, 470-475. [CrossRef] [PubMed]

89. Hu, M.; Wang, H.; Wang, Y.; Zhang, Y.; Wu, J.; Xu, B.; Gao, D.; Bi, J.; Fan, G. Alumina nanofiber-stabilized ruthenium nanoparticles: Highly efficient catalytic materials for hydrogen evolution from ammonia borane hydrolysis. Int. J. Hydrogen Energy 2017, 42, 24142-24149. [CrossRef]

90. Akbayrak, S.; Tanyıldızı, S.; Morkan, İ.; Özkar, S. Ruthenium(0) nanoparticles supported on nanotitania as highly active and reusable catalyst in hydrogen generation from the hydrolysis of ammonia borane. Int. J. Hydrogen Energy 2014, 39, 9628-9637. [CrossRef]

91. Kalkan, E.B.; Akbayrak, S.; Özkar, S. Ruthenium(0) nanoparticles supported on nanohafnia: A highly active and long-lived catalyst in hydrolytic dehydrogenation of ammonia borane. Mol. Catal. 2017, 430, 29-35. [CrossRef]

92. Wen, L.; Su, J.; Wu, X.; Cai, P.; Luo, W.; Cheng, G. Ruthenium supported on MIL-96: An efficient catalyst for hydrolytic dehydrogenation of ammonia borane for chemical hydrogen storage. Int. J. Hydrogen Energy 2014, 39, 17129-17135. [CrossRef]

93. Yang, K.; Zhou, L.; Yu, G.; Xiong, X.; Ye, M.; Li, Y.; Lu, D.; Pan, Y.; Chen, M.; Zhang, L.; et al. Ru nanoparticles supported on MIL-53(Cr, Al) as efficient catalysts for hydrogen generation from hydrolysis of ammonia borane. Int. J. Hydrogen Energy 2016, 41, 6300-6309. [CrossRef]

94. Zhang, S.; Zhou, L.; Chen, M. Amine-functionalized MIL-53(Al) with embedded ruthenium nanoparticles as a highly efficient catalyst for the hydrolytic dehydrogenation of ammonia borane. RSC Adv. 2018, 8, 12282-12291. [CrossRef]

95. Cui, P.; Ren, H.; Zhu, G. Ruthenium Inlaying Porous Aromatic Framework for Hydrogen Generation from Ammonia Borane. Front. Mater. 2019, 6, 223. [CrossRef]

96. Zhao, W.; Wang, R.; Wang, Y.; Feng, J.; Li, C.; Chen, G. Effect of LDH composition on the catalytic activity of Ru/LDH for the hydrolytic dehydrogenation of ammonia borane. Int. J. Hydrogen Energy 2019, 44, 14820-14830. [CrossRef] 
97. Qiu, X.; Liu, J.; Huang, P.; Qiu, S.; Weng, C.; Chu, H.; Zou, Y.; Xiang, C.; Xu, F.; Sun, L. Hydrolytic dehydrogenation of $\mathrm{NH}_{3} \mathrm{BH}_{3}$ catalyzed by ruthenium nanoparticles supported on magnesium-aluminum layered double-hydroxides. RSC Adv. 2020 10, 9996-10005. [CrossRef]

98. Wu, Z.; Duan, Y.; Ge, S.; Yip, A.C.K.; Yang, F.; Li, Y.; Dou, T. Promoting hydrolysis of ammonia borane over multiwalled carbon nanotube-supported Ru catalysts via hydrogen spillover. Catal. Commun. 2017, 91, 10-15. [CrossRef]

99. Zhang, L.; Wang, Y.; Li, J.; Ren, X.; Lv, H.; Su, X.; Hu, Y.; Xu, D.; Liu, B. Ultrasmall Ru Nanoclusters on Nitrogen-Enriched Hierarchically Porous Carbon Support as Remarkably Active Catalysts for Hydrolysis of Ammonia Borane. Chem CatChem 2018, 10, 4910-4916. [CrossRef]

100. Li, Y.-T.; Zhang, S.-H.; Zheng, G.-P.; Liu, P.; Peng, Z.-K.; Zheng, X.-C. Ultrafine Ru nanoparticles anchored to porous g-C3N4 as efficient catalysts for ammonia borane hydrolysis. Appl. Catal. A Gen. 2020, 595, 117511. [CrossRef]

101. Navlani-garcía, M.; Verma, P.; Kuwahara, Y.; Kamegawa, T. Visible-light-enhanced catalytic activity of Ru nanoparticles over carbon modified g-C3N4. J. Photochem. Photobiol. A 2018, 358, 327-333. [CrossRef]

102. Chen, G.; Wang, R.; Zhao, W.; Kang, B.; Gao, D.; Li, C.; Lee, J.Y. Effect of Ru crystal phase on the catalytic activity of hydrolytic dehydrogenation of ammonia borane. J. Power Sources 2018, 396, 148-154. [CrossRef]

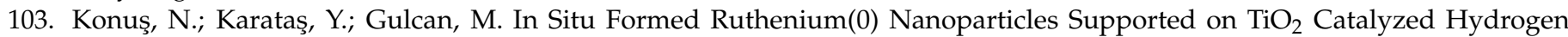
Generation from Aqueous Ammonia-Borane Solution at Room Temperature Under Air. Synth. React. Inorganic Met. Nano-Metal Chem. 2016, 46, 534-542. [CrossRef]

104. Wang, R.; Wang, Y.; Ren, M.; Sun, G.; Gao, D.; Chin Chong, Y.R.; Li, X.; Chen, G. Effect of ceria morphology on the catalytic activity of $\mathrm{Ru}$ /ceria for the dehydrogenation of ammonia borane. Int. J. Hydrogen Energy 2017, 42, 6757-6764. [CrossRef]

105. Nozaki, A.; Ueda, C.; Fujiwara, R.; Yamashita, A.; Yamamoto, H.; Morishita, M. Hydrogen Generation from Ammonia Borane over $\mathrm{Ru} /$ Nanoporous $\mathrm{CeO}_{2}$ Catalysts Prepared from Amorphous Alloys. Mater. Trans. 2019, 60, 845-848. [CrossRef]

106. Dhakshinamoorthy, A.; Li, Z.; Garcia, H. Catalysis and photocatalysis by metal organic frameworks. Chem. Soc. Rev. 2018, 47, 8134-8172. [CrossRef]

107. Pascanu, V.; González Miera, G.; Inge, A.K.; Martín-Matute, B. Metal-Organic Frameworks as Catalysts for Organic Synthesis: A Critical Perspective. J. Am. Chem. Soc. 2019, 141, 7223-7234. [CrossRef]

108. Ranocchiari, M.; Bokhoven, J.A. van Catalysis by metal-organic frameworks: Fundamentals and opportunities. Phys. Chem. Chem. Phys. 2011, 13, 6388-6396. [CrossRef]

109. Chandra, M.; Xu, Q. A high-performance hydrogen generation system: Transition metal-catalyzed dissociation and hydrolysis of ammonia-borane. J. Power Sources 2006, 156, 190-194. [CrossRef]

110. Rachiero, G.P.; Demirci, U.B.; Miele, P. Bimetallic RuCo and RuCu catalysts supported on $\gamma-\mathrm{Al}_{2} \mathrm{O}_{3}$. A comparative study of their activity in hydrolysis of ammonia-borane. Int. J. Hydrogen Energy 2011, 36, 7051-7065. [CrossRef]

111. Valero-Pedraza, M.-J.; Alligier, D.; Petit, E.; Cot, D.; Granier, D.; Adil, K.; Yot, P.G.; Demirci, U.B. Diammonium tetraborate dihydrate as hydrolytic by-product of ammonia borane in aqueous alkaline conditions. Int. J. Hydrogen Energy 2020, 45, 9927-9935. [CrossRef]

112. Yadav, M.; Xu, Q. Liquid-phase chemical hydrogen storage materials. Energy Environ. Sci. 2012, 5, 9698-9725. [CrossRef]

113. Lang, C.; Jia, Y.; Yao, X. Recent advances in liquid-phase chemical hydrogen storage. Energy Storage Mater. 2020, $26,290-312$. [CrossRef]

114. Liu, C.-H.; Wu, Y.-C.; Chou, C.-C.; Chen, B.-H.; Hsueh, C.-L.; Ku, J.-R.; Tsau, F. Hydrogen generated from hydrolysis of ammonia borane using cobalt and ruthenium based catalysts. Int. J. Hydrogen Energy 2012, 37, 2950-2959. [CrossRef]

115. Ramachandran, P.V.; Gagare, P.D. Preparation of ammonia borane in high yield and purity, methanolysis, and regeneration. Inorg. Chem. 2007, 46, 7810-7817. [CrossRef]

116. Sutton, A.D.; Burrell, A.K.; Dixon, D.A.; Garner III, E.B.; Gordon, J.C.; Nakagawa, T.; Ott, K.C.; Robinson, J.P.; Vasiliu, M. Regeneration of ammonia borane spent fuel by direct reaction with hydrazine and liquid ammonia. Science 2011, 331, 1426-1429. [CrossRef]

117. Hajari, A.; Roy, B.; Kumar, V.; Bishnoi, A.; Sharma, P. Regeneration of Supported Ammonia Borane to Achieve Higher Yield. ChemistrySelect 2021, 6, 1276-1282. [CrossRef] 